\title{
El abastecimiento con agua subterránea a la Colonia Clunia Sulpicia (Hispania CiteriorTarraconensis)
}

\author{
María Rosa Cuesta(1), Natalia Ayuso(2), José Antonio Cuchí(2), Miguel Ángel de la Iglesia ${ }^{(3)}$, Francisco Lera ${ }^{(2)}$, \\ Rafael Larma ${ }^{(4)}$, José Antonio Rausa ${ }^{(2)}$, Francesc Tuset ${ }^{(5)}$, Víctor Viñals $^{(2)}$ y José Luis Villarroel ${ }^{(2)}$
}

(1) Equipo de Investigación Yacimiento Arqueológico Colonia Clunia Sulpicia.

Casa de la Excavación. Virgen de Castro s/n, 09454-Peñalba de Castro, Burgos mr.cuestamoratinos@gmail.com

(2) Grupo de Tecnologías en Entornos hostiles (GTE). Universidad de Zaragoza. C/ Mariano Esquillor s/n, 50018-Zaragoza nayuso@unizar.es, cuchi@unizar.es, lera@unizar.es,21aspe.cer@gmail.com, victor@unizar.es, jlvilla@unizar.es

(3) Departamento de Teoría de la Arquitectura y Proyectos Arquitectónicos. Laboratorio de Paisaje Arquitectónico Patrimonial y Cultural. (LABPAP). Escuela Técnica Superior de Arquitectura. Universidad de Valladolid. Avenida de Salamanca 18, 47014-Valladolid iglesia@arq.uva.es

(4) Escuaín Topografía S.L. Calle Única s/n. 22362-Escuaín. escuain @escuain.top.

(5) Equip de Recerca Arqueològica i Arqueomètrica de la Universitat de Barcelona (ERAAUB). Facultat de Geografia i Historia. Universitat de Barcelona. C/. Montalegre 6, 08001-Barcelona ftuset@ub.edu.

\section{RESUMEN}

Hace 20 siglos, una autoridad romana fundó una ciudad en lo alto de un cerro testigo donde el hallazgo, por habilidad o casualidad, de un pequeño acuífero permitió el abastecimiento de agua. En época romana se perforaron pozos, de los que diecinueve Ilegaron a una cavidad natural. También se abrió una galería horizontal, para captar agua, y un drenaje en el teatro para eliminar aguas que molestaban. En algún momento, por razones naturales o artificiales, el nivel freático bajó y varios pozos se secaron, obligando al descenso de trabajadores y otras personas. Además de hacer obras complementarias dejaron abundantes grafitis y varias figuritas en barro en la cueva.

La ciudad no sobrevive a la Edad Media, los pozos son cegados y las ruinas sufren un proceso de expolio por las localidades vecinas. Recuperada su memoria en el siglo XVIII, en 1908 se redescubre cueva Román, una antigua galería de captación que da acceso a la cueva natural. Esta es explorada y topografiada por el grupo Espeleológico Ribereño desde 1980. A partir de 2013, el Grupo de Tecnologías en Entornos hostiles, de la Universidad de Zaragoza, realiza radiolocalizaciones sistemáticas para la apertura de un acceso directo a la cavidad. Además, se han hecho reconocimientos de inscripciones con escaneos de la cavidad y detalles específicos así como la instalación de dos estaciones de monitorización, exterior e interior, para analizar el funcionamiento hídrico del sistema y la evolución interior del contenido en $\mathrm{CO}_{2}$ del aire de la cavidad. La evolución del nivel piezométrico presenta oscilaciones relativamente importantes y se detecta un retraso de dos meses entre los momentos de fuertes Iluvias y el ascenso. El contenido en $\mathrm{CO}_{2}$ presenta una doble periodicidad, anual y diaria.

Palabras clave: Clunia, Cueva Román, karst, espeleología, hidrogeología.

\section{Groundwater supply for Colonia Clunia Sulpicia (Hispania Citerior Tarraconensis)}

\begin{abstract}
Twenty centuries ago, a Roman authority founded a city on top of an inselberg where the discovery, by skill or chance, of a small aquifer which allowed access to a water supply for the city. In Roman times wells were drilled, of which nineteen reached a natural cavity. A horizontal gallery for water supply was also opened up, and a drainage conduct in the theatre was made to eliminate storm water. At some point, for natural or artificial reasons, the water table dropped and several wells dried up, forcing the descent of workers and other people to do additional work and to carve abundant graffiti and several clay figurines. The city did not survive the Middle Ages, the wells became cesspits and the ruins were plundered by neighbouring villages. It recovered its memory in the eighteenth century, in 1908 a Roman cave was rediscovered, the old water supply gallery, which gives access to the natural cave. This has been explored and surveyed by the Grupo Espeleológico Ribereño since 1980. From 2013, the Grupo de Technologías in Entornos Hostiles (University of Zaragoza) has carried out systematic radiolocation for the opening up of a direct access to the cavity. In addition, recognition of inscriptions with cavity scans and specific details have been made as well as the installation of two monitoring stations, both inside and outside the cavity to analyze the water performance of the system and the internal evolution of the $\mathrm{CO}_{2}$ content of the air in the cavity. The evolution of the piezometric level presents relatively important oscillations and a delay of two months is detected between the moments of heavy rains and the increase of water levels in the cavity. The $\mathrm{CO}_{2}$ content has a double periodicity, annual and daily.
\end{abstract}

Keywords: Clunia, hydrogeology, karst, Román cave, speleology. 


\section{Introducción}

La captación de agua subterránea durante la época romana mediante pozos y galerías fue una práctica muy extendida de la que se presentan abundantes ejemplos en Cuesta (2012). Un estudio detallado de galerías clásicas en la península lbérica se presenta en Martínez Jiménez (2013). Estudios locales serían los de la fuente Grande de Ocaña (López Camacho et al., 2005), el acueducto subterráneo de Torralba, Murcia (Gris et al., 2002) o la galería documentada cerca de la antigua ciudad de Acinipo, hoy próxima a Ronda (Millán, 2019). Otras localidades se situaban directamente sobre el acuífero. Dejando aparte los balnearios de aguas termales, como Bath o Sao Pedro do Sul, algunas ciudades captaban aguas subterráneas mediante pozos o galerías artificiales de acuíferos situados bajo ellas, como Bracara Augusta (Martins et al., 2012), Carmo (Millán, 2018 a y b) y la Cova Urbana bajo Tarraco (Arnavat, 1998, Martínez Jiménez, 2013). Esta última ciudad, y las presentadas por Parise y Sammarco (2015), en el sur de Italia, están situados sobre materiales kárstificados.

Un interesante ejemplo es la ciudad romana denominada Colonia Clunia Sulpicia, cuyas ruinas se encuentran en la provincia de Burgos (Figura 1) en las proximidades de la pequeña localidad de Peñalba de Castro.

La ciudad se levantaba sobre un cerro testigo de techo plano, ligeramente vertiente al norte, y una superficie de unas 110 ha. Su cota máxima, a 1022 m.s.n.m, levanta unos $60 \mathrm{~m}$ sobre la llanura circundante, drenada por el modesto río Arandilla y sus afluentes.

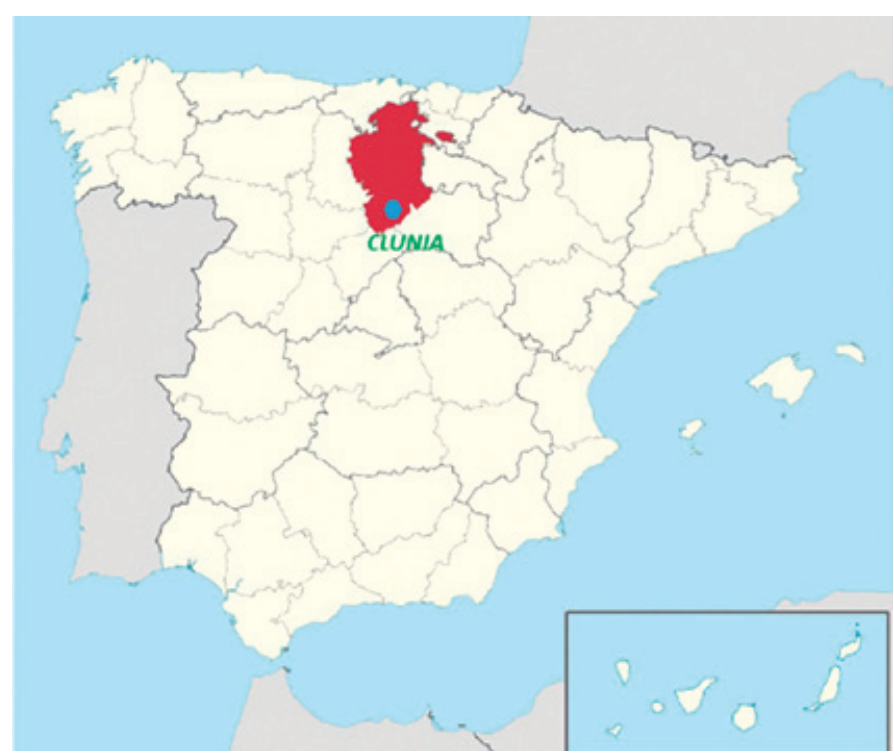

Figura 1. Localización de Colonia Clunia Sulpicia.

Figure 1. Location of Colonia Clunia Sulpicia.
El presente trabajo se centra sobre las características hidrogeológicas de un acuífero situado bajo la ciudad romana y en el abastecimiento de agua a la misma, descrito inicialmente por Cuesta (2102) y Martos et al., (2018).

\section{Historia de Clunia}

Colonia Clunia Sulpicia se encuentra cerca de la ciudad arévaca homónima citada en las guerras de Numancia y Sertorio. Se asume que la ciudad romana se funda en tiempos de Augusto (Palol, 1994). Con Tiberio, la ciudad romana ya está constituida y acuñaba moneda, con estatuto de municipio. Plinio la menciona en su Historia Natural, al hablar de los Conventus luridici de la Tarraconense, que fueron establecidos con la reforma administrativa y territorial que tuvo lugar con Claudio. Clunia sirvió de refugio durante el final del mandato de Nerón, a Servio Sulpicio Galba, efímero emperador del siglo I, de quien toma su nombre y, tal vez, el origen de su categoría de colonia. Actuó como un importante centro administrativo (de la Iglesia y Tuset, 2010 y 2012) y nudo de caminos entre el Mediterráneo, la Lusitania y el Cantábrico. También está próxima a las canteras de Espejón ya explotadas en esta época.

La ciudad se monumentaliza en el siglo I, contando con foro, tres termas (Los Arcos I y II y las denominadas del Foro) y un teatro (Figuras 2 y 3 ). Para éste, construido a finales del s. I d.C, se ha estimado un aforo de unos 8.000-9.000 espectadores (Cuesta, 2012). A partir de este dato, se supone que la ciudad y su entorno pudieron alcanzar una población de unos 30.000 habitantes.

A partir del siglo II, la ciudad comienza un largo declive, comprobado arqueológicamente. En el 169 d.C. el teatro fue parcialmente desmontado y transformado en un anfiteatro. El conjunto termal de Los Arcos I sufrió importantes transformaciones, con reocupaciones hasta época de Teodosio e incluso fue transformado en un taller de terra sigillata. Algo muy similar sucedió con Los Arcos II. En las tabernas del Foro, ya a finales de siglo II, se produjo una caída de la actividad aunque algunas perduran hasta el siglo III. La basílica se usó hasta finales del siglo IV. Aunque algunos edificios se siguieron utilizando como tales, otros se usaron ya como necrópolis en el siglo IV.

Salvo la derivada de los trabajos arqueológicos, la información sobre la Clunia romana es bastante limitada en fuentes y epigrafía. En el siglo III, la ciudad es mencionada en los itinerarios clásicos de caminos. En el siglo V, el cristianismo ya se ha implantado en la ciudad (Palol, 1983). 


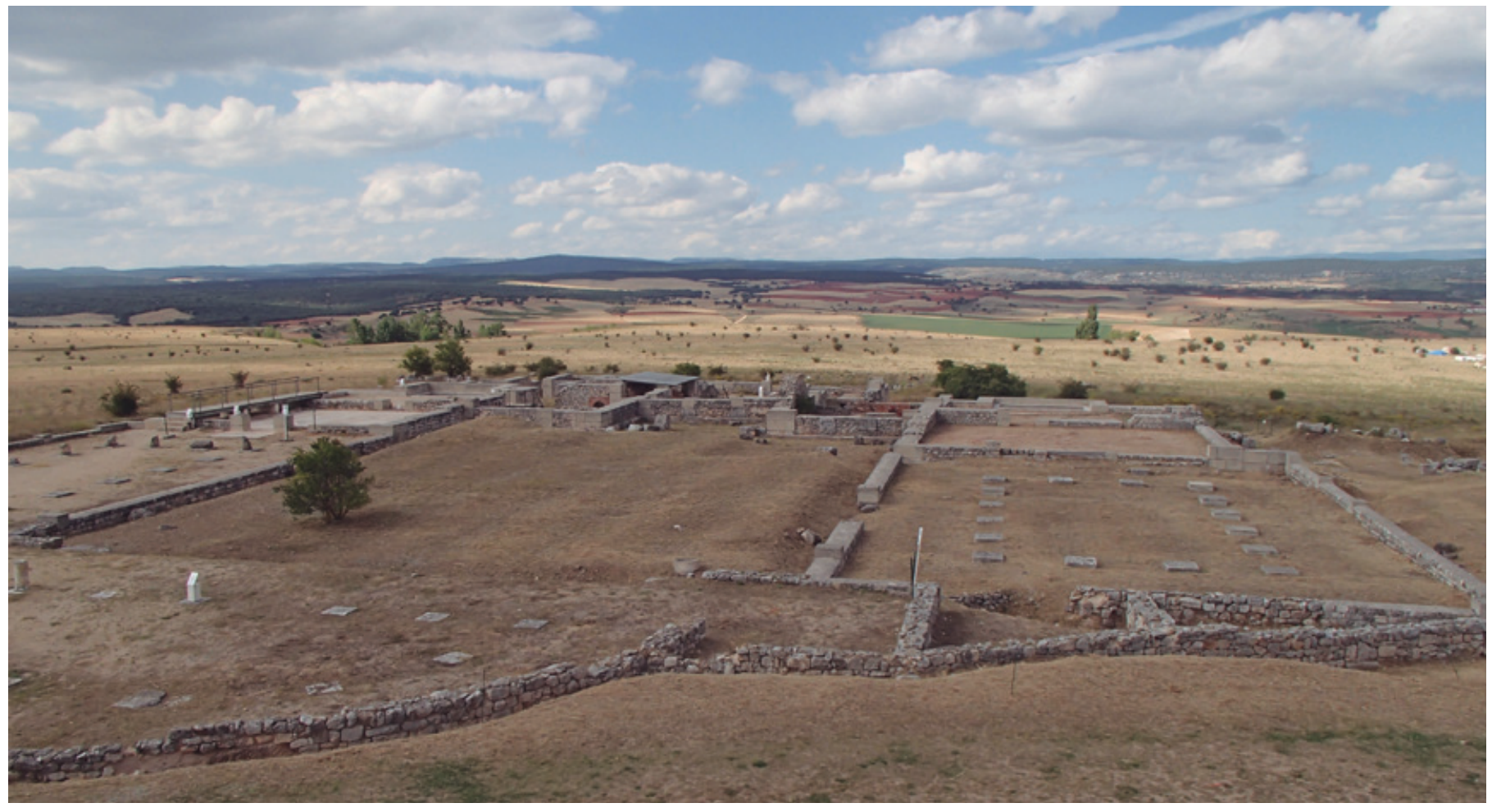

Figura 2. Termas de Clunia.

Figure 2. Baths of Clunia.

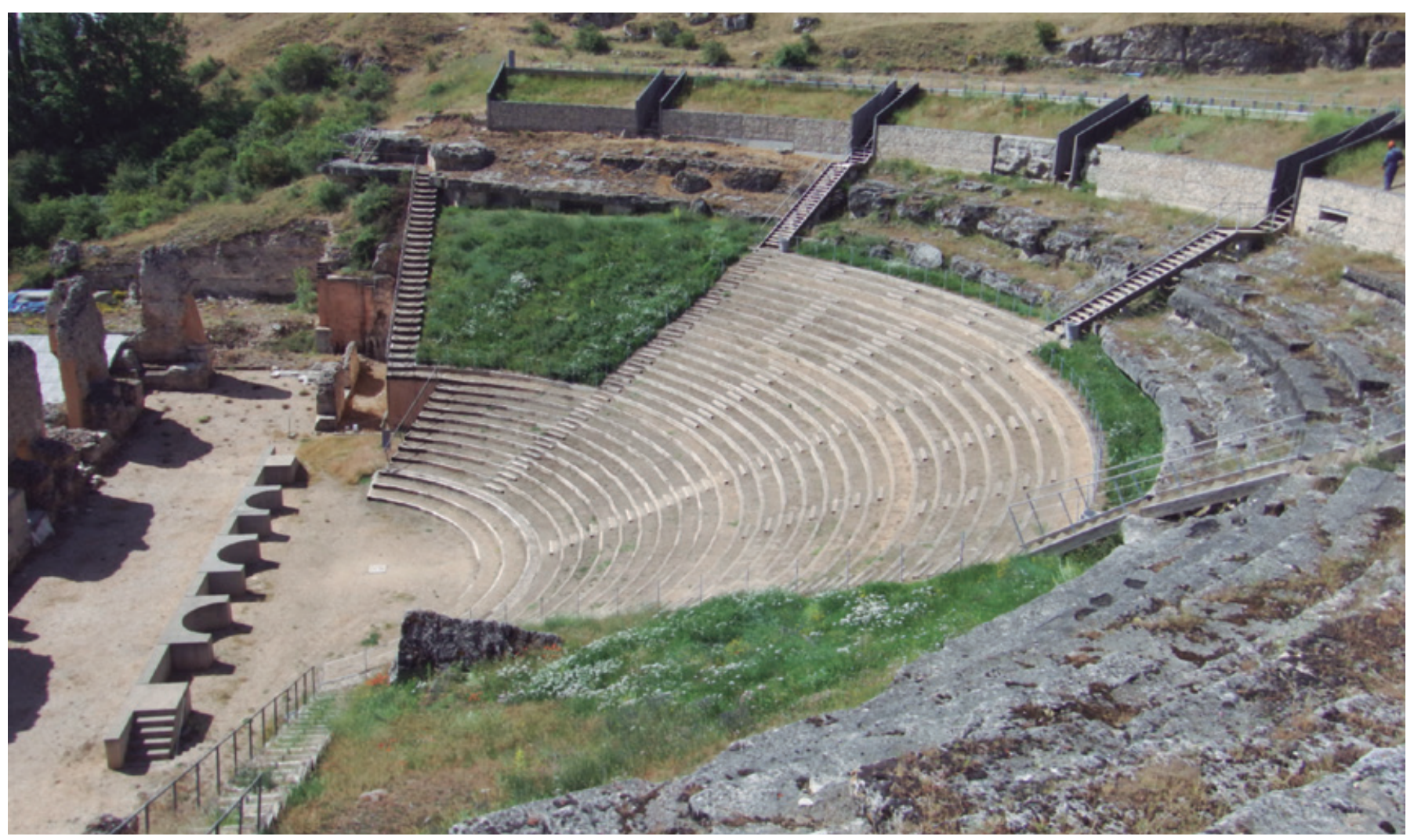

Figura 3. Teatro de Clunia.

Figure 3. Theatre of Clunia. 


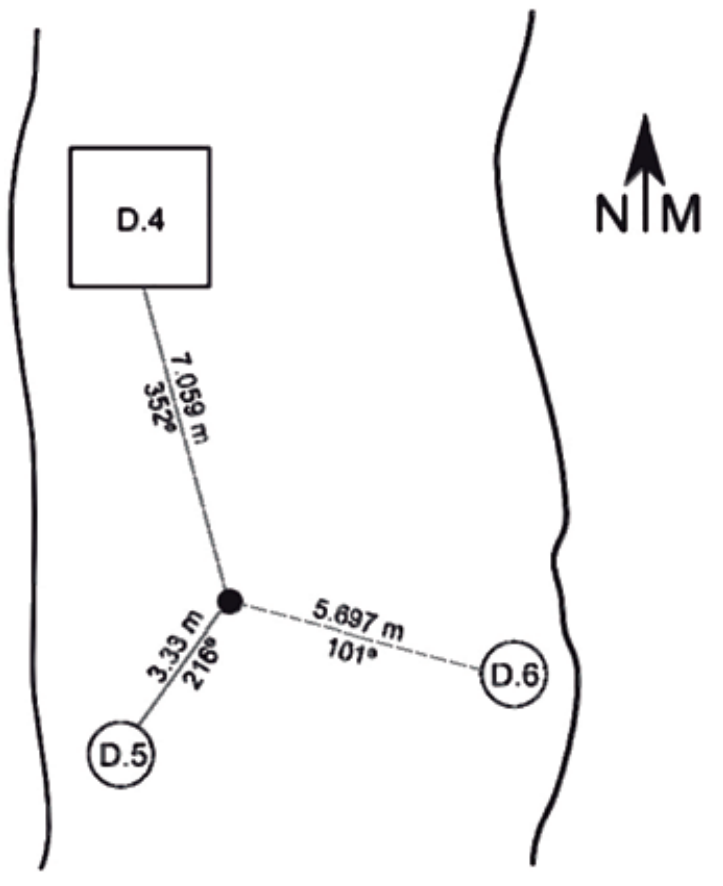

Figura 4. Radiolocalización. Año 2013.

Figure 4. Radiolocation. Year 2013.

Los cronistas musulmanes la citan en su conquista de España (Cuesta, 2011), indicando que la población, al menos nominalmente, subsiste tras la conquista musulmana. En la Crónica de Alfonso III se lista entre las localidades tomadas por este rey (Ortega, 2019). Repoblada por Gonzalo Fernández en el 912 (Camacho, 2014), es conquistada otras dos veces por los musulmanes, la última en tiempo de Abderramán III. Después, las ruinas de Clunia se convierten en cantera para el inmediato núcleo de Peñalba de Castro y la vecina localidad de Coruña del Conde, que tiene un castillo medieval.

A partir del siglo XVII, basándose en fuentes clásicas, surge un interés por localizar esta ciudad romana. Los primeros visitantes ilustrados, como Juan Loperráez en 1778, quedan sorprendidos por el grado de desmantelamiento de la ciudad. A principios del siglo $X X$, en 1913, el interés por las ruinas es asumido por Vicente Hinojal. Narciso Sentenach e Ignacio Calvo inician unas primeras excavaciones (Calvo, 1916), seguidas por los trabajos más sistemáticos de Blas Taracena entre 19301935. A partir de 1960, Pedro de Palol retoma las excavaciones. Posteriormente, Francesc Tuset y Miguel Ángel de la Iglesia dirigen los trabajos arqueológicos y de restauración desde 1995 hasta la actualidad.

Añadió interés al yacimiento el descubrimiento fortuito, en 1908, de la hoy conocida como cueva Román, cuando el vecino Román Juez excavaba una bodega y accedió a un túnel artificial romano que daba paso a una cavidad natural aprovechada en el pasado. La ex-

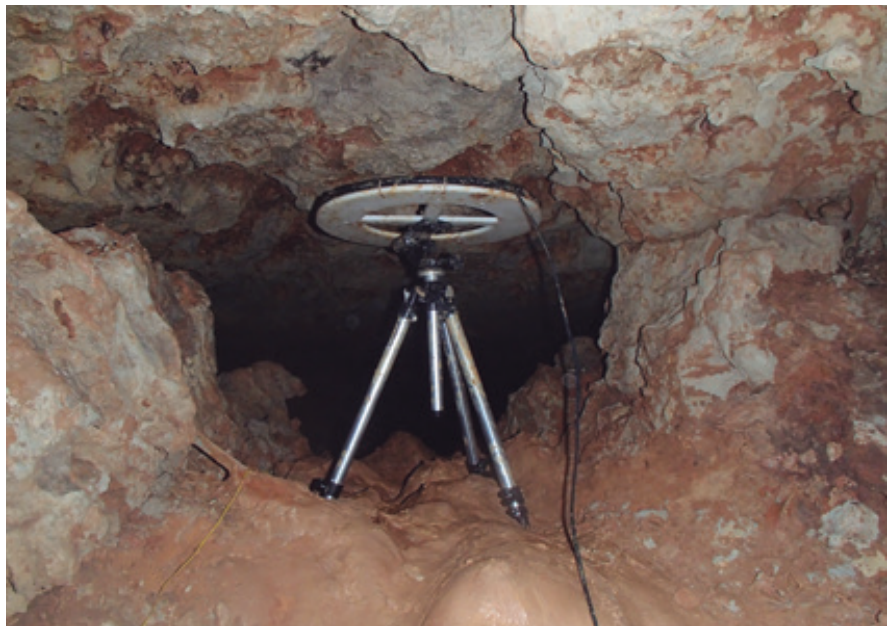

Figura 5. Radiolocalizador en interior de cueva.

Figure 5. Beacon of radilocation inside the cave.

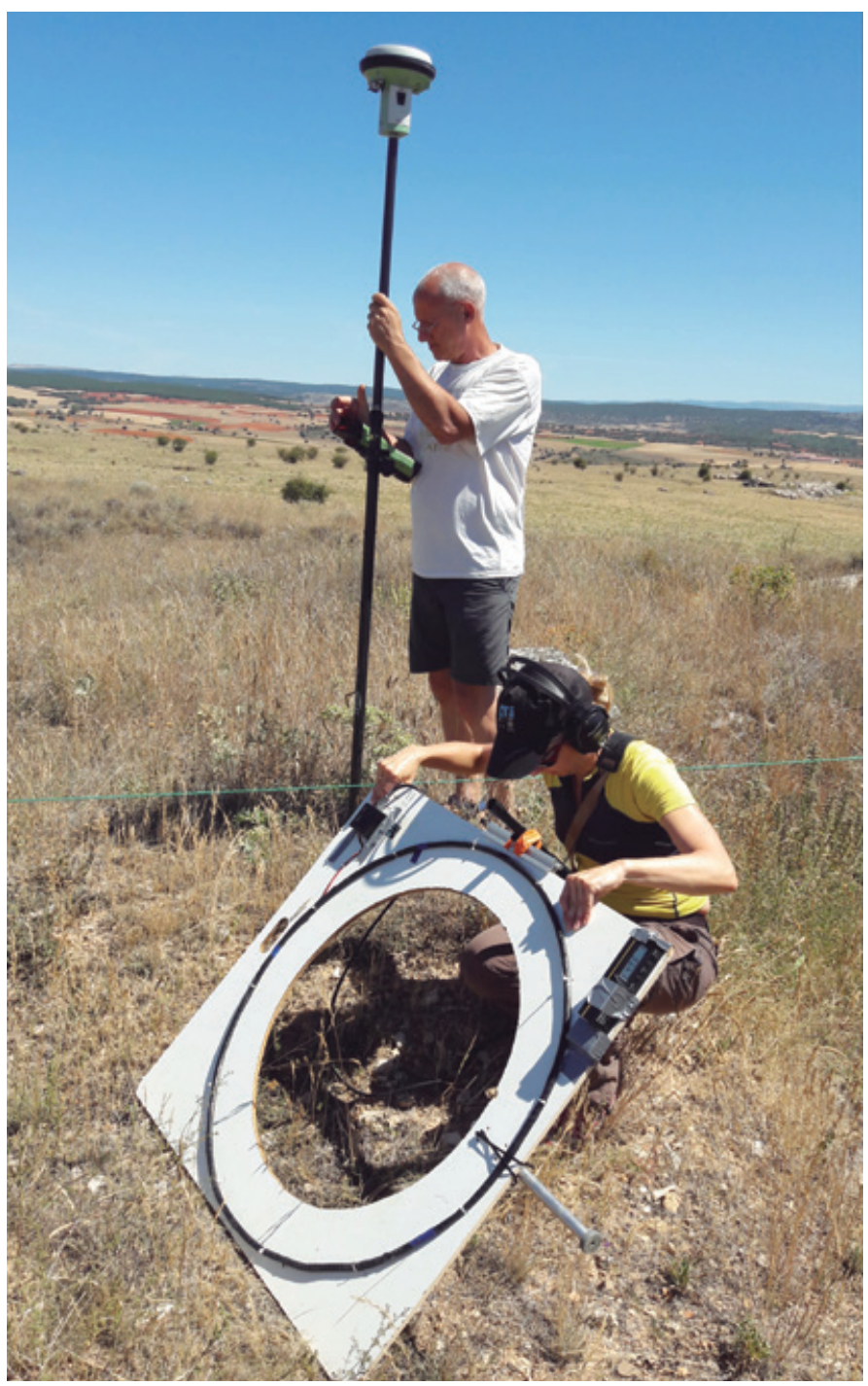

Figura 6. Antena de radiolocalización en superficie.

Figure 6. Radiolocation antenna at surface. 


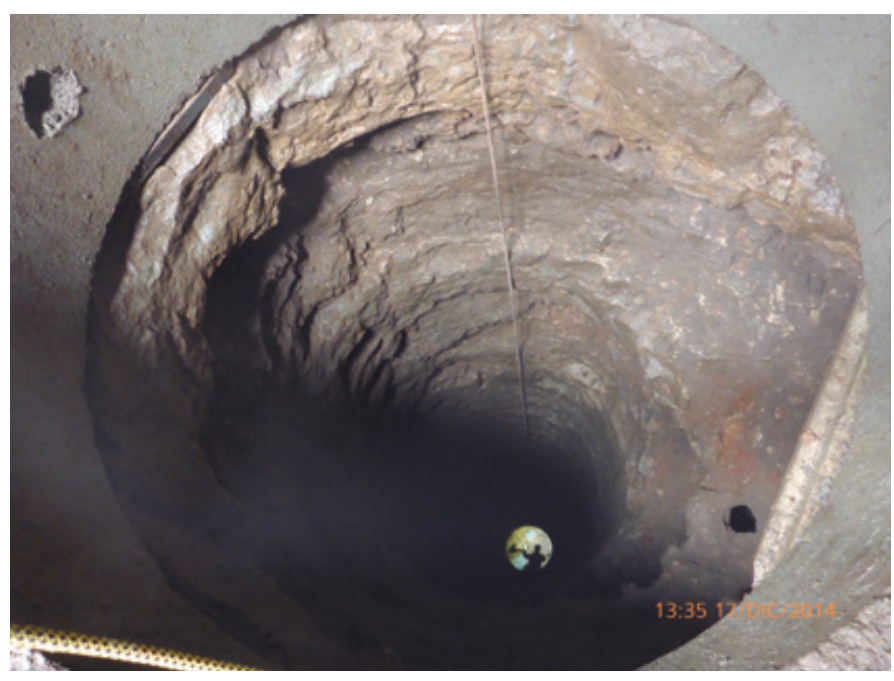

Figura 7. Aspecto actual del pozo D6 tras su excavación y acondicionamiento.

Figure 7. Current appearance of well D6 after its excavation and conditioning.

ploración temprana de esta cavidad tuvo claros tintes de aventura dados los medios de la época (Hinojal, 1913). En 1930, Blas Taracena realizó una excavación en la boca del túnel encontrando una compuerta con finalidad hídrica (Taracena et al., 1947).

\section{Actividades contemporáneas en Cueva Román}

En la década de 1960 se inician las primeras exploraciones espeleológicas, de las que se conocen algunas topografías parciales del Grupo Edelweiss de Burgos. Desde 1967, pero sobre todo en la década de 1980, el Grupo Espeleológico Ribereño (GER) de Aranda de Duero explora la cavidad y realiza una detallada topografía. Descubren varias bocas de pozos cegadas, sólo visibles desde el interior, así como un amplio número de inscripciones, algunas figurillas en barro y otros restos diversos (GER, 1995). A partir de estos hallazgos se comienza a hablar de un santuario priápico ( $\mathrm{Pa}-$ lol, 1986, 1988 a y b).

El interés arqueológico y la dificultad de acceso por cueva Román al interior suscitaron el interés de acceder mediante la localización exterior y apertura de uno de los pozos cegados. Apoyándose en la topografía del GER se realizaron diversos trabajos de geofísica de exterior: Sondeos Eléctricos Verticales (Porres Benito, 2003; Porres Benito et al., 2016; Valdés y Reina, 2004 y 2006) y gravimetría (González Díaz, 2008). En 2011 se realiza un estudio de geofísica magnética, resistividad eléctrica y georradar sobre una zona al SO de los edificios de las termas y hacia la casaTaracena, pero no se localiza la boca de algún pozo desde el exterior.

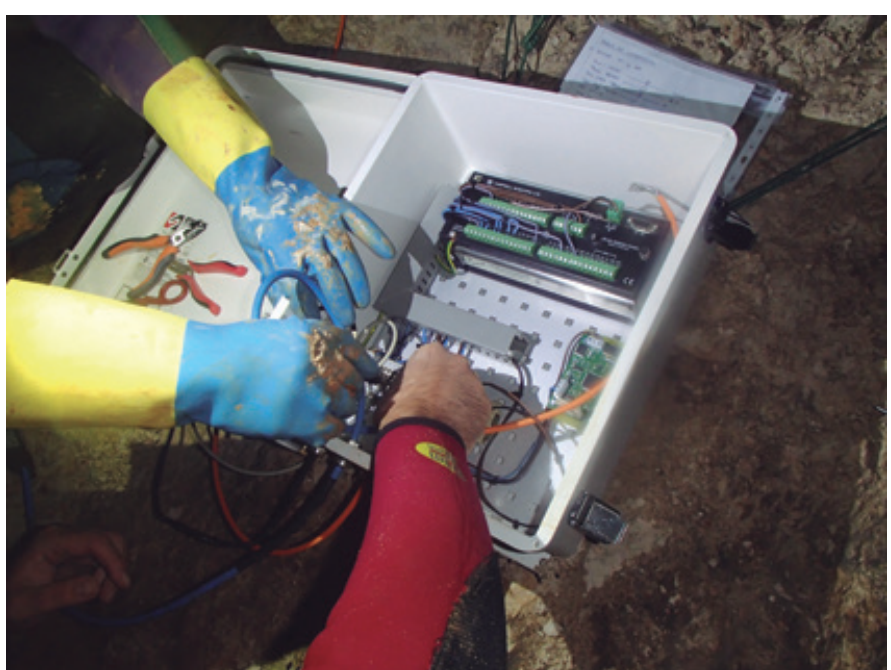

Figura 8. Detalle de la instalación del módulo registrador de la ERPA. Figure 8. Detail of the installation of the ERPA recorder module.

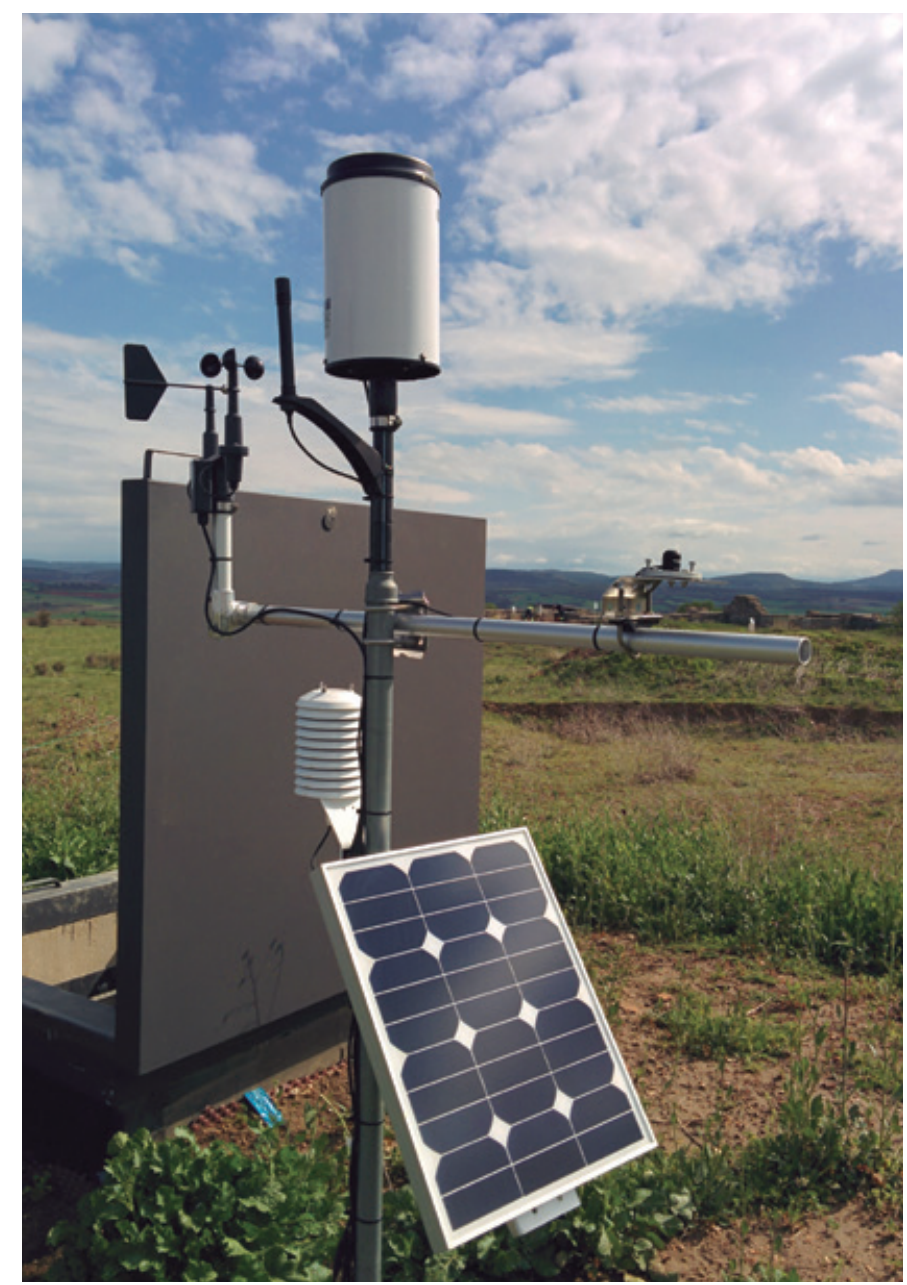

Figura 9. EMET y cierre exterior del pozo D6.

Figure 9. EMET and external closure of well D6. 


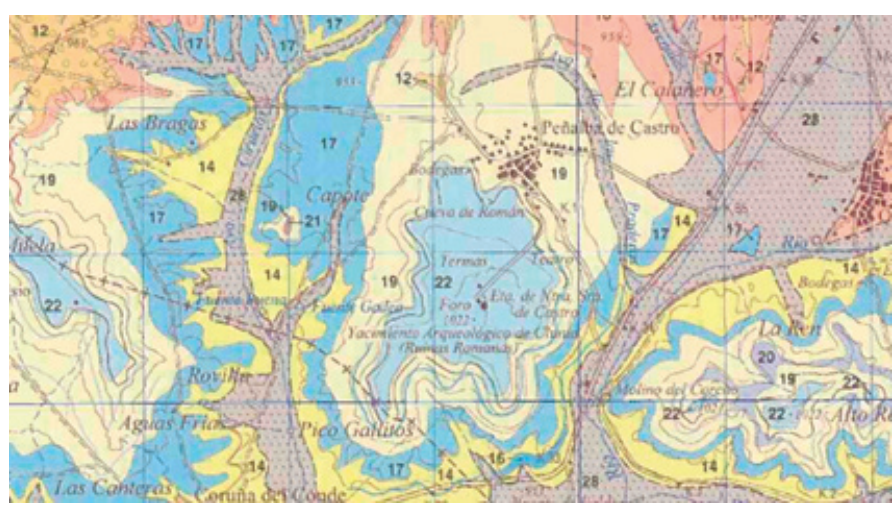

Figura 10. Mapa geológico de Clunia, según IGME (2008). 17. Calizas inferiores del Páramo (P1). 19. Limos arcillosos con glaebulas carbonatadas y calcimorfos. 22. Calizas superior del Páramo (P2)

Figure 10. Geological map of Clunia by IGME (2008). Lower limestone of the Páramo (P1). 19. Clay slime with carbonated and calcimorphic glaebulas. 22. Upper limestone of the Paramo (P2).

En julio de 2004, el Grupo de Tecnologías en Entornos hostiles (GTE) de la Universidad de Zaragoza realiza una primera radiolocalización, con un equipo de diseño propio desde el cono interior del pozo C3 (Ayuso et al., 2010). En octubre de 2011, la Dirección de la excavación vuelve a contactar con el GTE. En julio de 2013, con el apoyo de un equipo de comunicaciones inalámbricos TEDRA, se radiolocaliza un punto estratégico en la sala entre los pozos D4, D5 y D6 (Figuras 4, 5 y 6). En este momento también se recogieron cinco registradores Hobo Pro, para temperatura y humedad relativa que habían sido instalados en agosto de 2003.

A partir de la información obtenida, la Dirección de la excavación tomó la decisión de abrir el pozo D6. Durante 2015 se realizó la excavación del relleno del pozo, que tiene un diámetro medio de 1,4 m y cuyos resultados se presentan en Tuset et al., (2015). En diciembre se alcanzó la cavidad natural a $27 \mathrm{~m}$ de profundidad (Figura 7) y al año siguiente se instaló un cierre estanco en el exterior del pozo junto con un sistema de descenso espeleológico. Además, cerca de la boca se colocó una estación meteorológica (EMET) para lluvia (Young 52202), temperatura y humedad relativa (Rotronic HC2S3), viento (Young 030025), radiación (Campbell Scientific CS300) y presión (Vaisala PTB110) que vierten sobre un datalogger Campbell CR800. (Figuras 8 y 9). También se estableció comunicación mediante genéfono con el interior y alimentación eléctrica desde placas solares a ERPA y EMET; se instalaron las dos estaciones en red, accesibles desde internet para la descarga de datos y funciones de mantenimiento.

Los trabajos posteriores se han centrado en la exploración detallada de la cavidad, la localización de inscripciones y otros artefactos arqueológicos, la ra- diolocalización sistemática de pozos, la realización de trabajos de topografía en 2 y $3 \mathrm{D}$ en zonas selectas del yacimiento superficial y la cavidad, el escaneo de algunas de figuras e inscripciones así como la realización de documentales (ver por ejemplo: https://youtu. be/MJXPW03bgel).

\section{Geología de Clunia}

Clunia se encuentra en el borde septentrional de la cuenca terciaria del Duero, a unos $7 \mathrm{~km}$ en línea recta de las estribaciones de la Cordillera Ibérica, sector Cameros-Demanda con materiales del Jurásico y Cretácico. Destacan localmente las calizas de la Fm Espejón del Batoniense medio y superior (Wilde, 1990) y las gravas silíceas y arenas caoliníferas de la $\mathrm{Fm}$. Utrillas (Cretácico medio). Los conglomerados abigarrados de la facies Garumninense y calizas blancas del Jurásico fueron ampliamente arrancadas de las canteras de Espejón para roca ornamental desde época romana (Puche y González-Aguado, 1992; García Entero, et al., 2018).

La erosión en varias fases de estos materiales mesozoicos rellenó la cubeta del Duero al final del Terciario, formando cuerpos subhorizontales, salvo en el borde de la cuenca, con frecuentes acuñaciones, cambios laterales de facies (Ordoñez et al., 1976; Molina, 1977; Armenteros, 1986; Molina y Armenteros, 1986; Benito Calvo y Pérez González, 2007; IGME, 2008). En el borde de las sierras, los materiales son más groseros, conglomerados y arenas, pasando rápidamente a facies más finas y lacustres con episodios edáficos y evidencias de procesos kársticos. Posteriormente, el río Arandilla y otros cauces cercanos se unieron a la red fluvial exorreica de la cuenca del Duero y se inició un proceso erosivo, que fue dejando cerros aislados como el Alto del Cuerno, Llano Muela y el ocupado por Clunia. Éste presenta una característica forma en estrella siguiendo diaclasas de posible tipo distensivo en direcciones NNO-SSE y NE-SO, similar a lo que se observa en Llano Muela.

El cerro de Clunia está formado por tres unidades subhorizontales del Mioceno continental de la cuenca del Duero. La Figura 10 muestra el mapa geológico del entorno inmediato de la ciudad, tomado de IGME (2008).

En la base se encuentran las calizas inferiores del Páramo (unidad P1). Sobre éstas, se presenta un nivel de limos arcillosos de color claro con glaébulas carbonatadas y calcimorfos por procesos de bioturbación, edafización y carbonatación edáfica. A techo del cerro, sobre el nivel limoso, se encuentra un nuevo nivel calcáreo (calizas superiores del Páramo, Unidad P2) del 


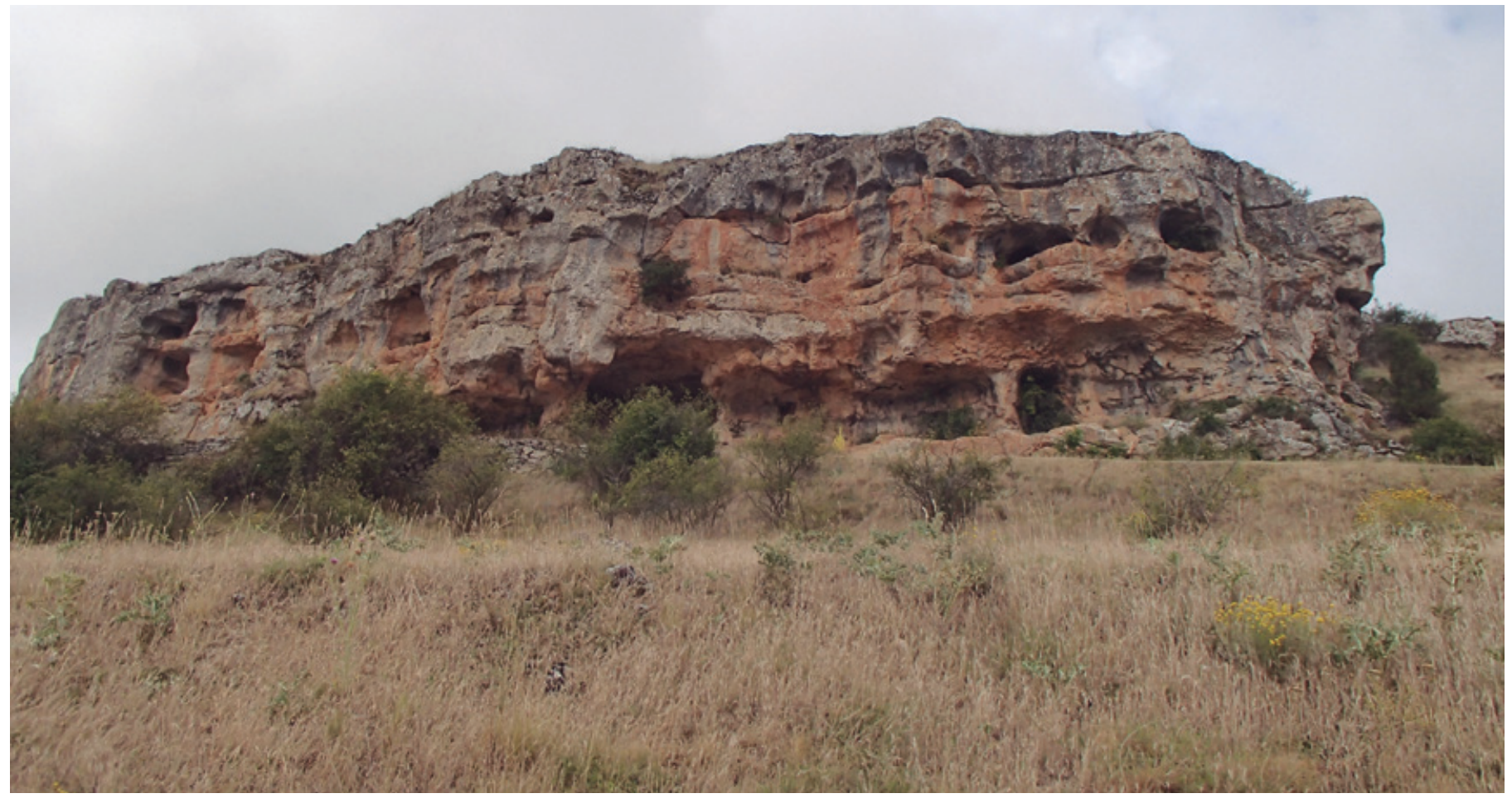

Figura 11. Nivel de calizas P2.

Figure 11. Limestone level P2.

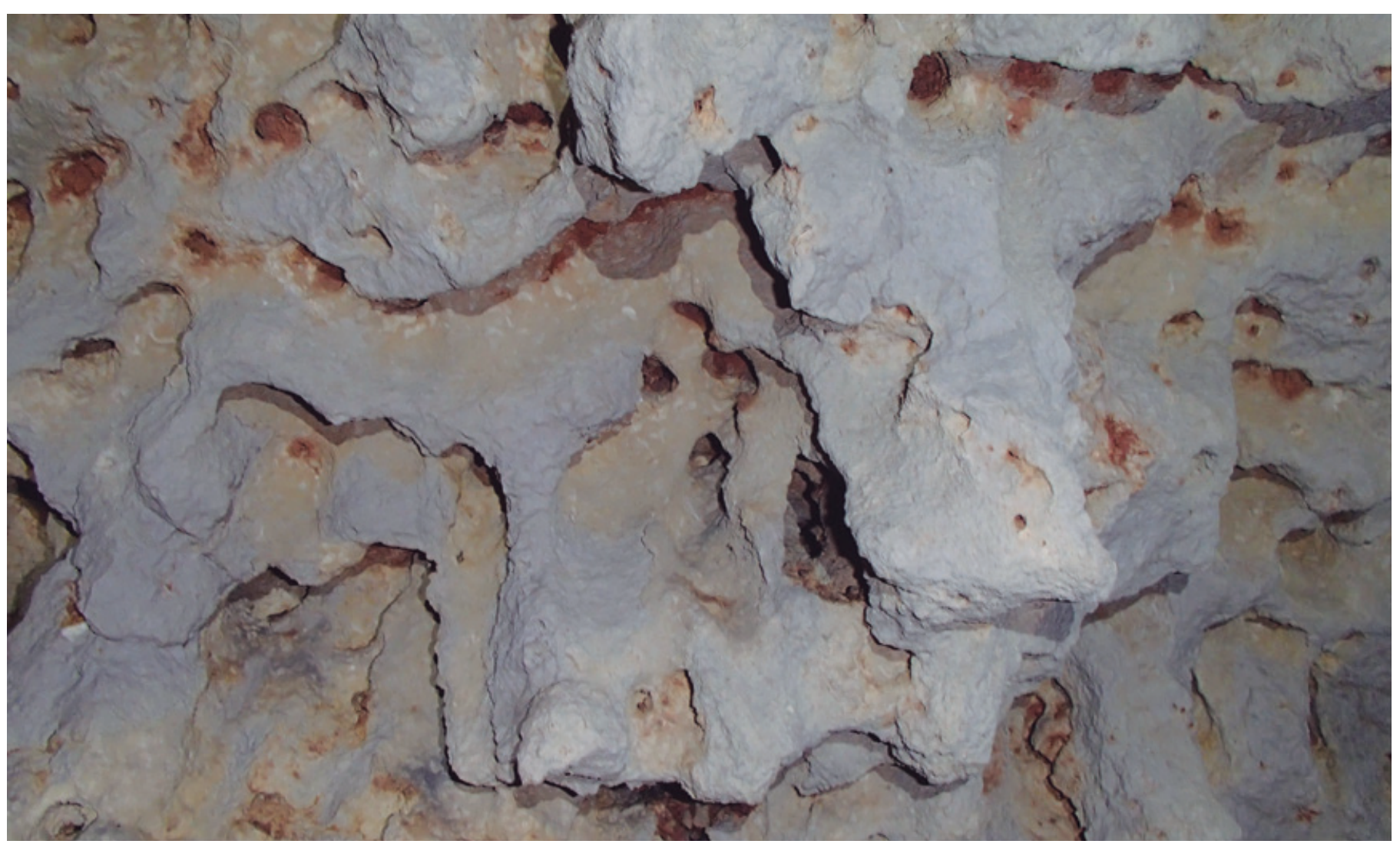

Figura 12. Microtubos radiculares de la caliza P2.

Figure 12. Root microtubes of limestone P2. 


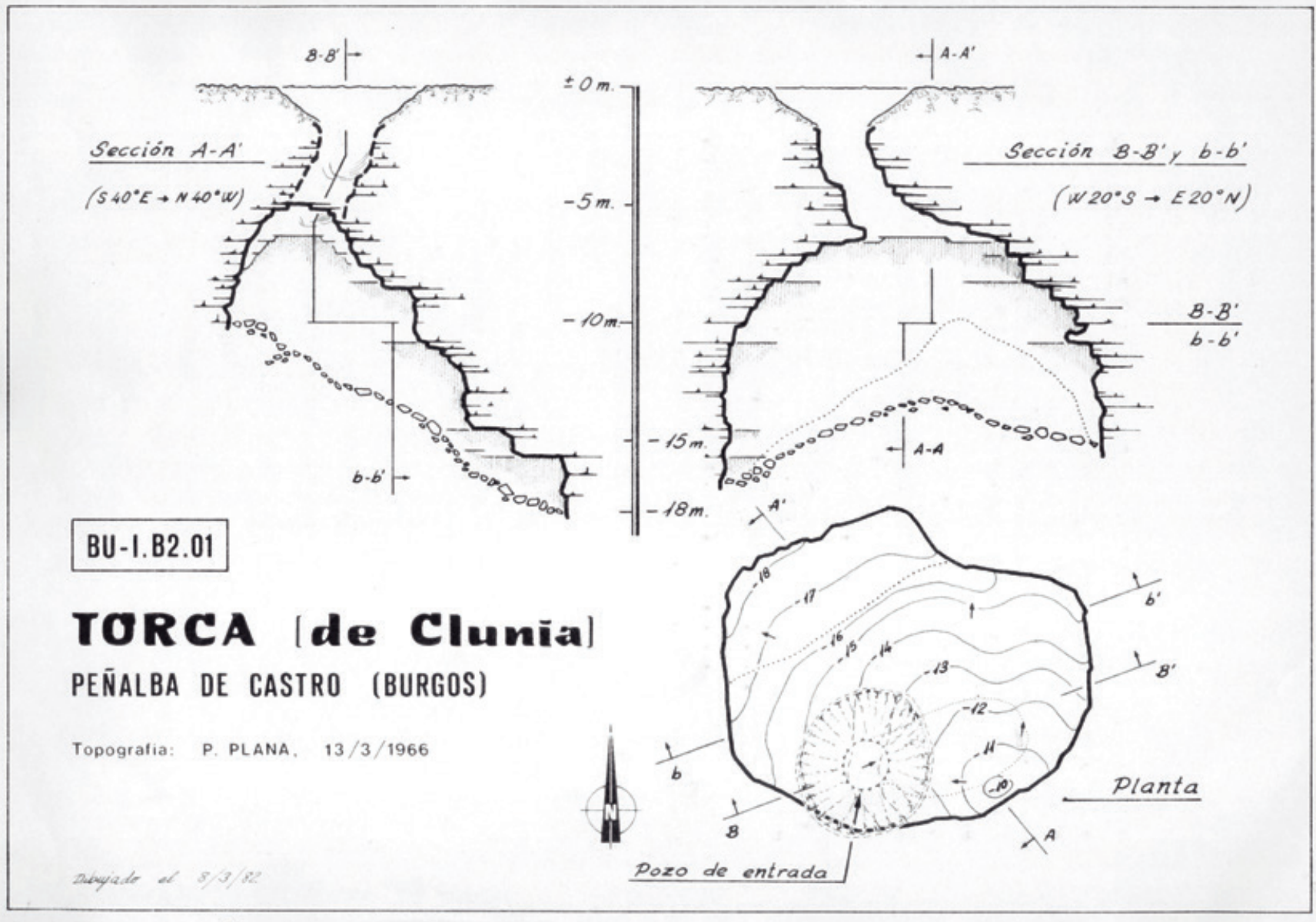

Figura 13. Topografía de la Torca de Clunia,1966, realizada por P. Plana (Grupo Edelweiss, Burgos).

Figure 13. Topography of the Torca de Clunia, 1966, by Pedro Plana (Edelweiss Group, Burgos).

Vallesiense-Turoliense que dan un claro resalte en el paisaje (Figura 11). Son margocalizas nodulares y calizas lacustres de tipo micrítico y de color gris claro en fresco que oscurece por alteración. En estratos de potencia métrica, tiene unos $30 \mathrm{~m}$ de espesor, aunque se sugieren diferencias locales de potencia y compacidad (Valdés y Reina, 2004). La caliza P2 presenta planorbisy otros gasterópodos lacustres y abundantes tubificaciones verticales de tipo radiciforme (Figura 12). Ambos niveles calizos, P1 y P2, fueron utilizados como canteras en época romana, mientras que el nivel limoso ha sido profusamente excavado para las bodegas en $\mathrm{Pe}$ ñalba de Castro.

Los fenómenos de karstificación son antiguos en la zona, señalados incluso antes del exorreísmo de la cuenca y relacionados con las superficies de erosión del Plioceno, cuando las facies que afloran en Clunia estaban conectadas lateralmente con la Cordillera Ibérica (Ordoñez et al., 1976; Molina, 1977; Molina y Armenteros, 1986).
Hoy la superficie actual del cerro de Clunia está muy recubierta por restos de edificaciones históricas, utilizadas posteriormente como canteras de expolio y campos de cultivo, pero se observa algún rasgo exokárstico. El más significativo es la Torca, dolina en ventana de una profundidad máxima de 17,24 m (H·30. X: 468755. Y: 4625259. Z: 1012) representada ya en los planos de Zuaznávar (siglo XVIII) y Sentenach (1914) presentados en Rodríguez Ceballos (2016). En mediciones realizadas por el GTE en 2019 se ha obtenido un volumen interior libre de $624 \mathrm{~m}^{3}$ indicando un importante volumen inicial. La figura 13 presenta una topografía realizada en 1966 por el Grupo Espeleológico Edelweiss de Burgos.

En la superficie del cerro se localizan otras pequeñas depresiones cuyo origen, dolina o pozo relleno, es de difícil discriminación. La más importante es una depresión en embudo que se encuentra sobre la proyección del cono D4. (H30. X: 469243. Y: 4625675. Z: 1018). Se especula que ésta fuera una dolina natural que hubiera servido como acceso previo a la cavidad y al agua. 


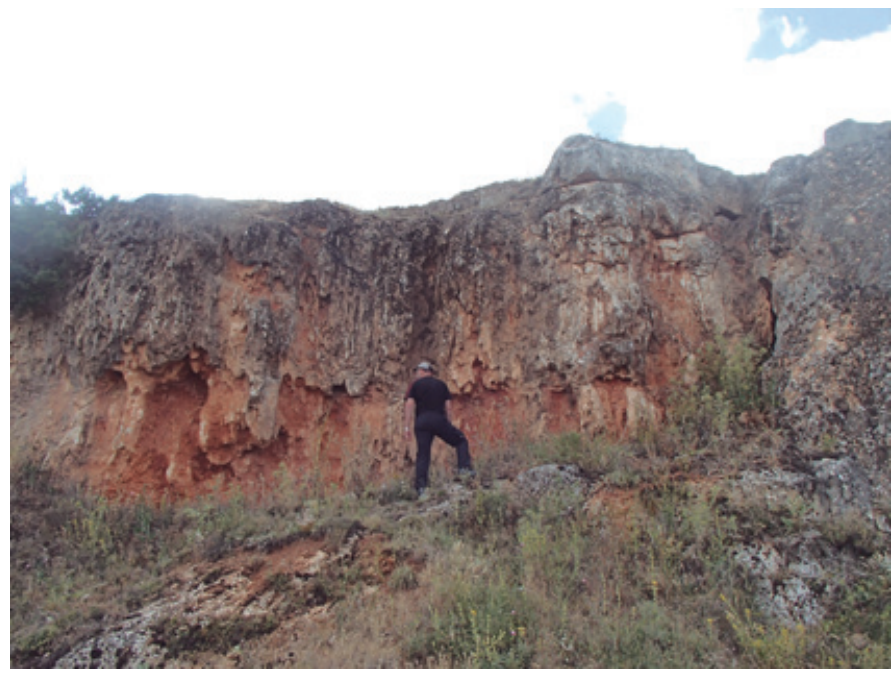

Figura 14. Oquedades y conductos subverticales rellenos de terra rossa cerca del teatro.

Figure 14. Cavities and sub-vertical ducts filled with terra rossa, near the theatre.

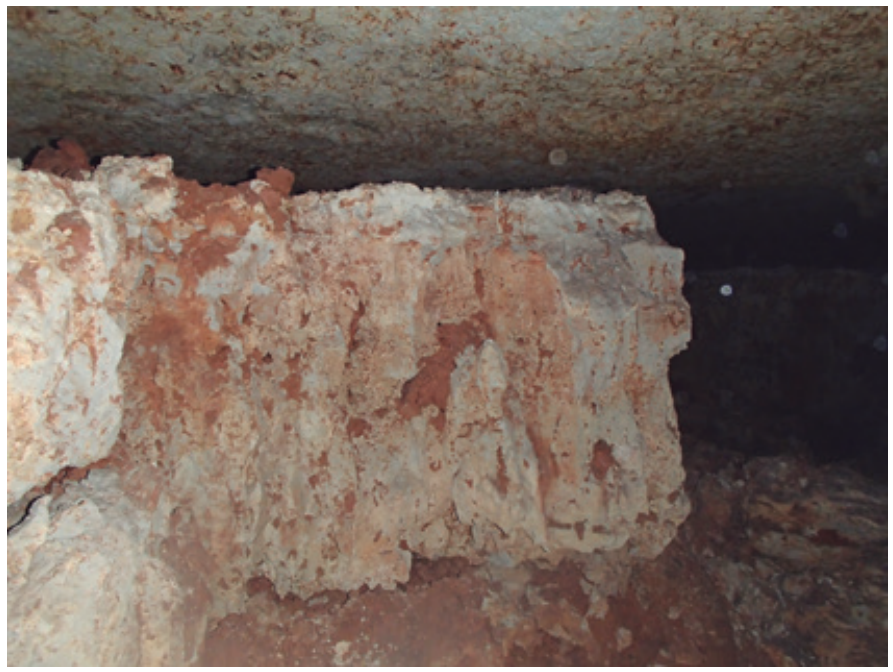

Figura 15. Oquedades y conductos subverticales rellenos de terra rossa en zona D4-D6.

Figure 15. Cavities and sub-vertical ducts filled with terra rossa. Cave at zone D4-D6.

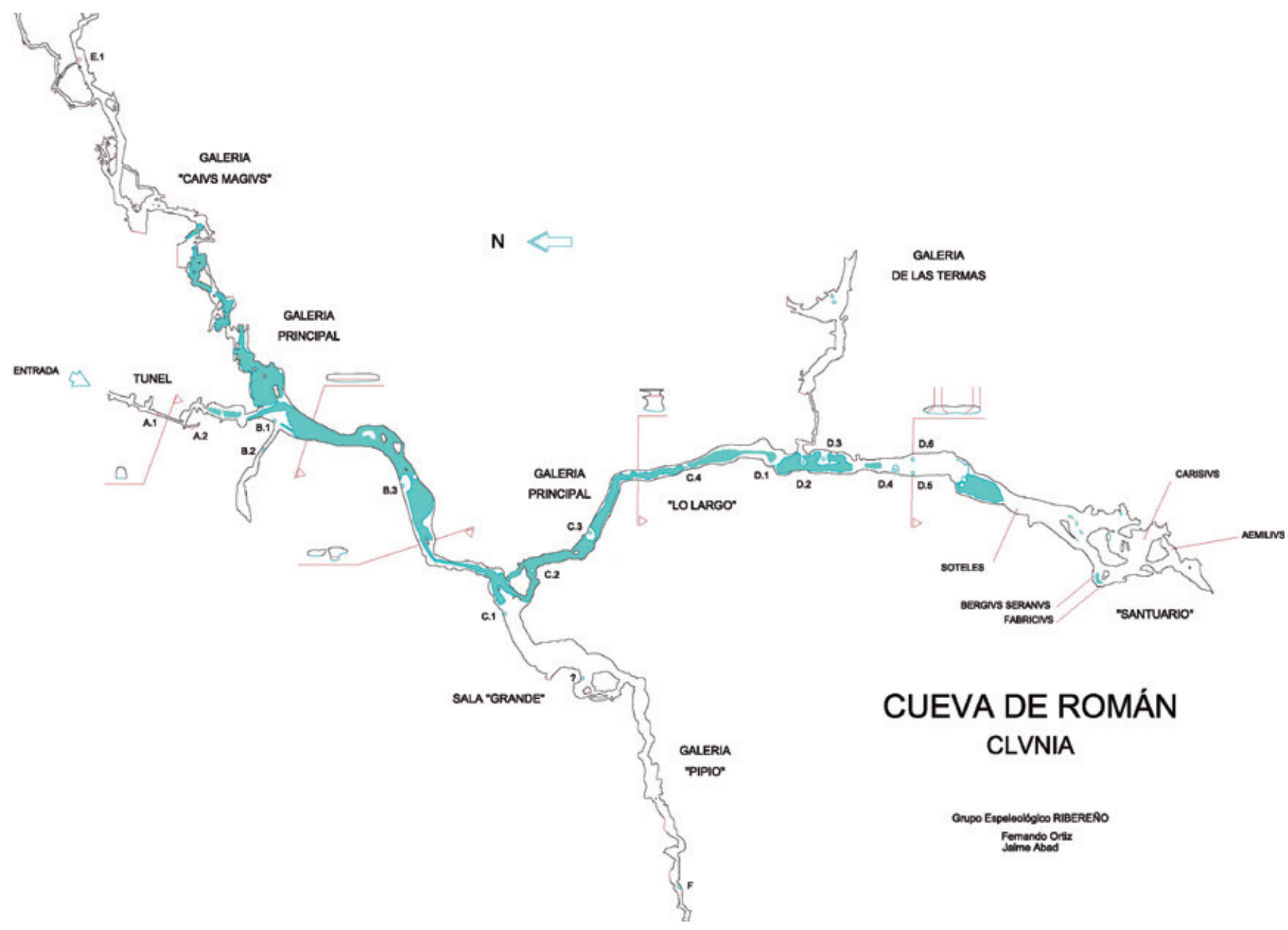

Figura 16. Topografía de cueva Román. Grupo Espeleológico Ribereño por F. Ortiz y J. Abad. Figure 16. Román cave topography. Grupo Espeleológico Ribereño by F. Ortiz and J. Abad. 


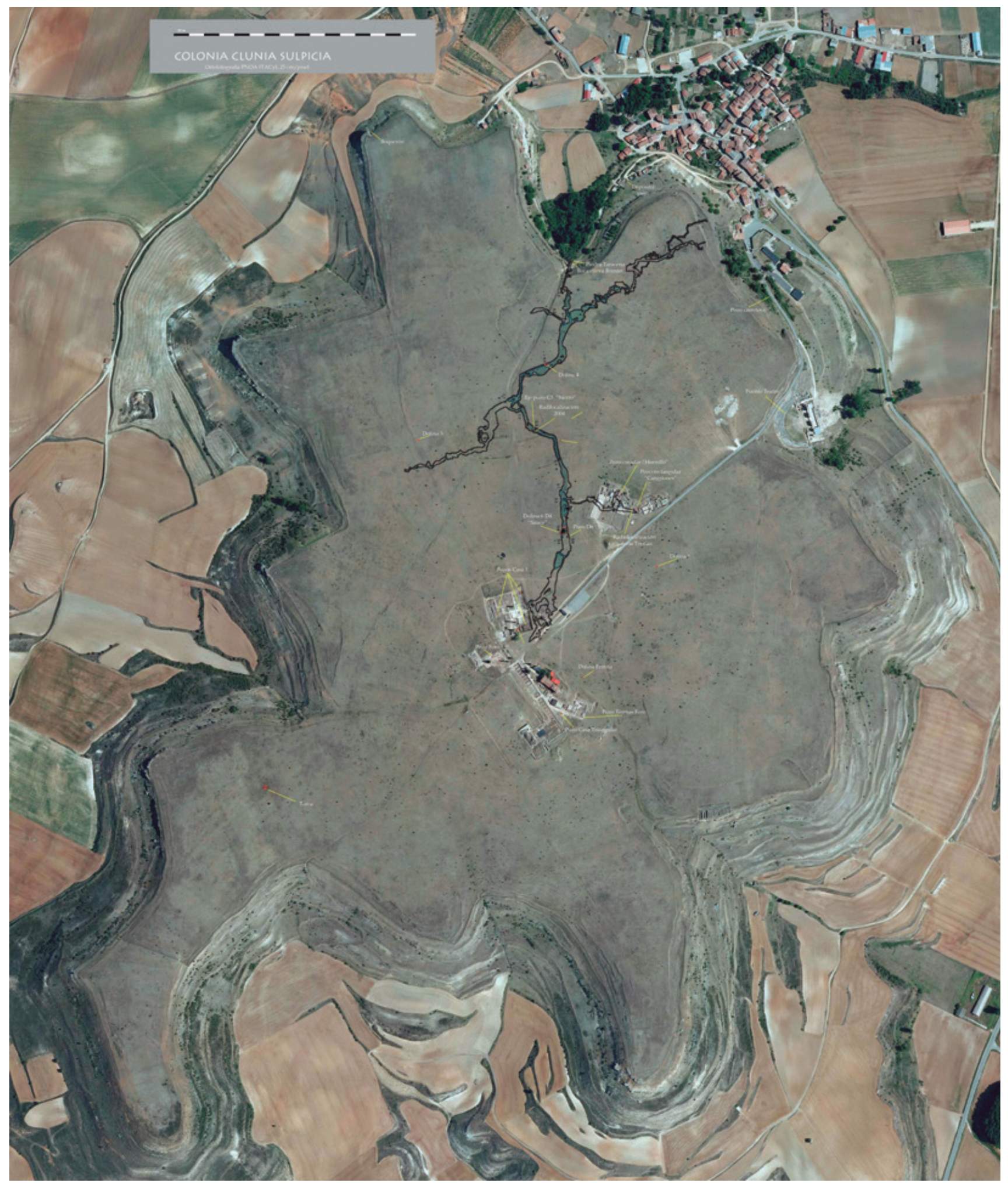

Figura 17. Superposición de la topografía del GER de la cavidad, ligeramente corregida por radiolocalización y declinación magnética, sobre la imagen georeferenciada del cerro de Clunia. Se muestran los diferentes pozos radiolocalizados. La Torca es el punto aislado situado al suroeste.

Figure 17. Superposition of the GER topography of the cavity, slightly corrected by radiolocation and magnetic declination, on the geo-referenced image of the Clunia hill. The different radiolocalized wells are shown. La Torca is the isolated point located to the southwest. 


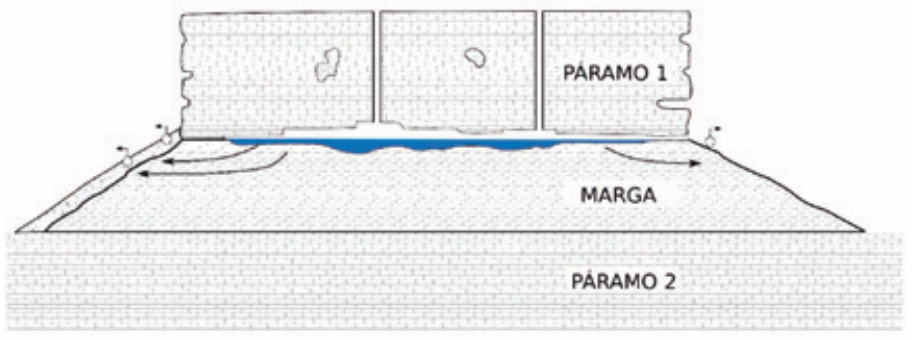

Figura 18. Modelo conceptual hidrogeológico del cerro de Clunia. Figure 18. Hydrogeological conceptual model of the hill of Clunia.

IGME (2008) señala la presencia de cavidades verticales irregulares y bolsones rellenos de terra rossa, visible, por ejemplo, junto al teatro romano (Figura 14), y también en el interior (Figura 15). Algunos cerros cercanos presentan un abundante lapiaz oqueroso que, posiblemente, también debía formar la superficie de Clunia antes de la ocupación romana.

Varias cavidades horizontales, en su mayoría muy modestas como Cuevas ciegas, se abren en este nivel calizo superior. La más importante es Cueva Román, accesible por una galería artificial romana y a la que se accedía por diversos pozos excavados en esta época y, desde 2015, por el pozo D6. La cavidad explorada por el GER (1986 a y b), fue topografía por Fernando Ortiz y Jaime Abad en condiciones francamente difíciles. EI resultado (Figura 16) es de muy buena calidad.

La superposición de la topografía de la cavidad sobre la imagen aérea se muestra en la figura 17. Se ha sugerido una relación entre la cavidad y el urbanismo de la ciudad, así como una conexión directa entre el tramo con mayor concentración de inscripciones y figuritas con la casa de Taracena que, hasta el presente, no se ha confirmado.

\section{Hidrogeología de Clunia}

La hidrogeología se compone de dos acuíferos. En la Ilanura que circunda a la ciudad romana, existe un extenso acuífero, la unidad 0.2.09 (Burgos-Aranda), con recarga directa y desde la Cordillera Ibérica (IGME, 2008). Sus niveles piezométricos se señalan bajo la cota 900 m s.n.m, por debajo del techo de la unidad Páramo P1. De esta se suministra Peñalba de Castro mediante un sondeo, perforado hasta-180 m junto a la fuente del

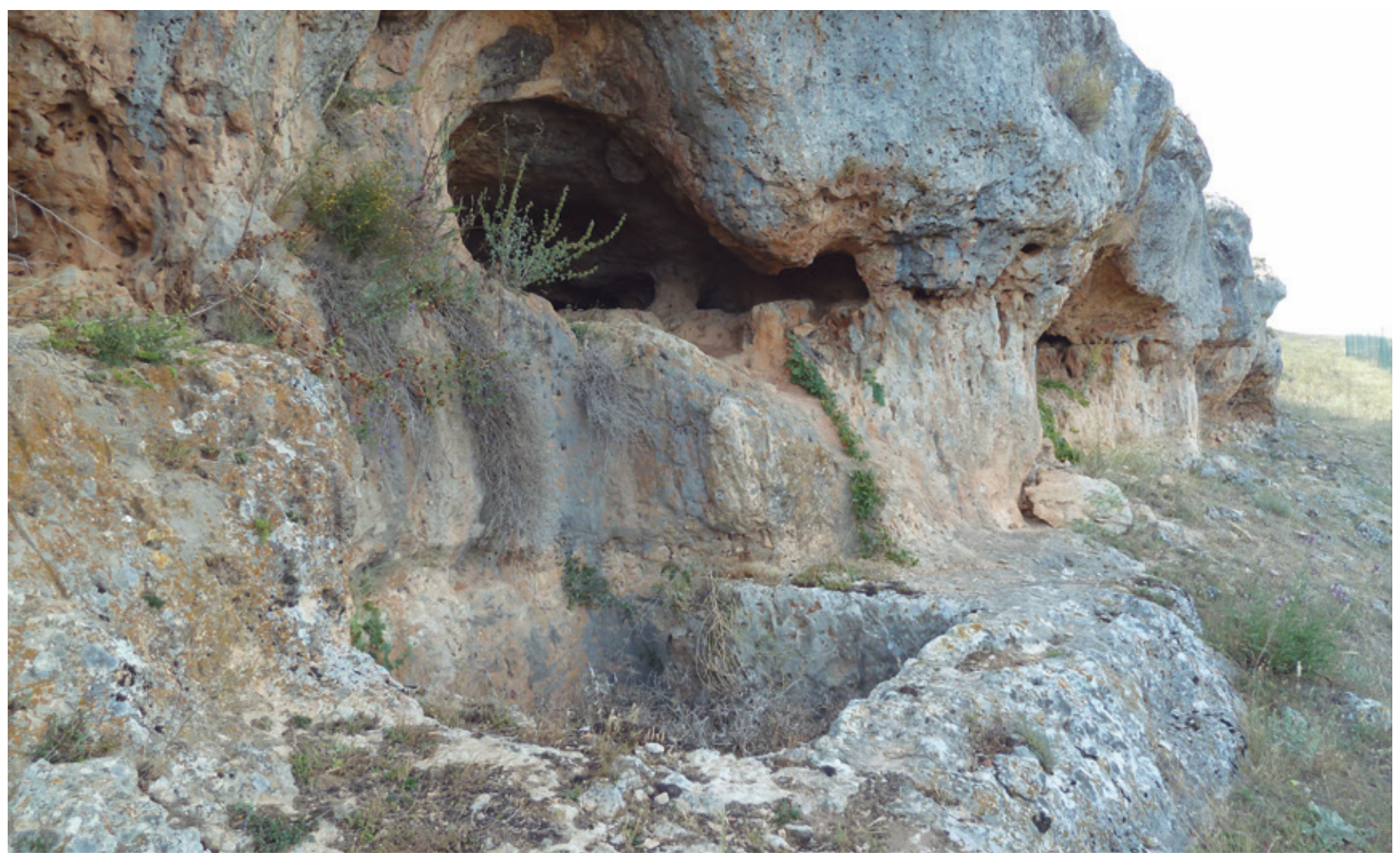

Figura 19. Conducto de flujo kárstico y cisterna tallada en sector Cuevas Ciegas.

Figure 19. Karst flow duct and carved cistern in the Cuevas Ciegas sector. 


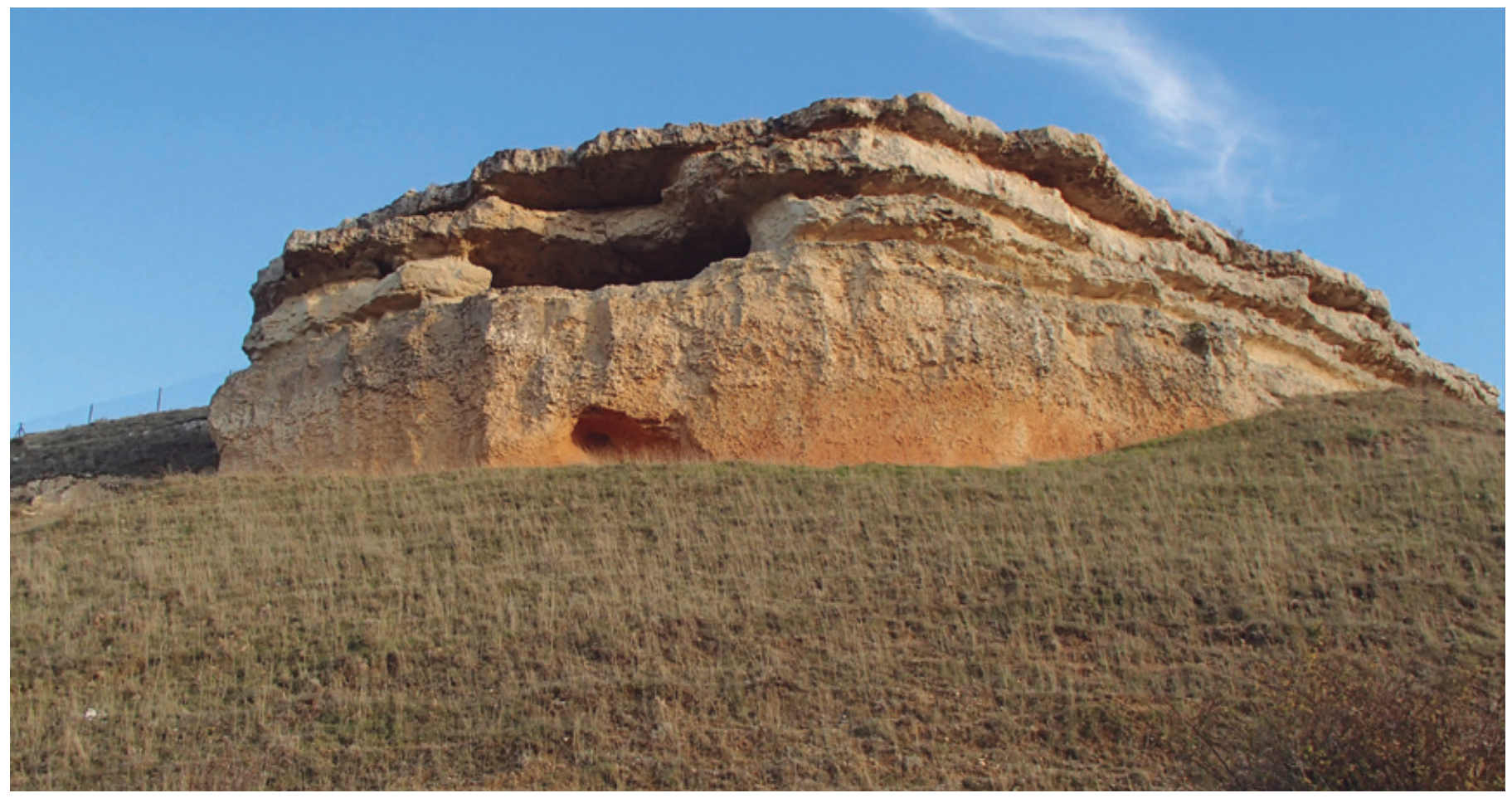

Figura 20. Cavidades de El Boquerón. Sector NO del cerro de Clunia.

Figure 20. Cavities of El Boquerón. Sector NO of the hill of Clunia.

Pilón (H30; X: 469337; Y: 4626345; Z: 919 m.s.n.m). El agua apareció a los $80 \mathrm{~m}$ y ascendió a $15 \mathrm{~m}$ de la superficie. También de este acuífero, al oeste del cerro surgen fuente Gadea y fuente Buena, de donde se suministra la vecina localidad de Coruña del Conde.

En el propio cerro, existe una segunda unidad, mucho más modesta que no parece tener ninguna relación con el acuífero inferior. Se alberga en la base de las calizas de la unidad P2, sobre las margas intermedias. Es un acuífero muy modesto, con rasgos kársticos en cuanto a la morfología. Es de tipo libre y sólo recarga por la lluvia directa sobre el cerro. La figura 18 presenta un modelo conceptual de la hidrogeología del cerro de Clunia.

Se observan tres tipos de porosidades. La de mayor tamaño se corresponde con las grandes cavidades, de las que hay dos subtipos. Uno está representado por los conductos de flujo, de forma relativamente cilíndrica. Ejemplo son las cavidades de Cuevas ciegas, donde históricamente se han tallado canalizaciones y una cisterna (Figura 19) e, incluso hoy día, se señala la existencia de flujos temporales tras fuertes Iluvias. EI segundo tipo son las cavidades estratiformes, de baja altura y gran extensión. Un ejemplo se puede observar, en el exterior en la zona de El Boquerón, en el noroeste del cerro (Figura 20), aparentemente una cavidad exhumada. Dentro de la cueva hay varias zonas similares.
El segundo tipo de porosidad está representado por los conductos subverticales de origen radiciforme, en parte rellenos de terra rossa (Figuras 12 y 15) que juegan un papel importante en el flujo en la zona no saturada y deben también de tenerlo en la zona saturada. Por último, hay una porosidad de pequeña escala constituida por los poros de la matriz de la margocaliza.

Como se ha señalado, este acuífero está colgado dado que su base sería el nivel limo arcilloso cuyo techo está a media ladera. Las descargas se producen por la fuente de Peñalba que vierte directamente al depósito viejo de la localidad, y por la alcantarilla del teatro romano que pasa bajo la escena. La parte superior del graderío de éste (ver la Figura 3) está tallada en las calizas superiores, pero la escena y las primeras filas lo hacen en la margas infrayacentes lo que produce una molesta salida de agua que originó la necesidad de obras específicas de drenaje. De hecho, en el graderío del teatro hay actualmente un pequeño manantial secundario a techo de los materiales margo arcillosos (988,8 m s.n.m).

Además, hay un rezume perimetral al cerro que discurre por el coluvión de la ladera, sugerido por freatofitas en varios lugares, detectado en los sondeos para el nuevo museo del yacimiento y captado para la casa de la excavación, en la carretera de acceso, a aproximadamente 930 m s.n.m. 


\section{Descripción de Cueva Román}

La cavidad, cuya topografía y toponimia corresponde a la figura 16, está formada por la galería principal, a la que se accede por la galería romana (Figura 21) y un corto tramo natural, parcialmente excavado, con un pequeño sifón temporal. La galería principal tiene varios tramos acuáticos. El inicio de $\mathrm{B} 1$ a $\mathrm{C} 1$, es un tramo en bóveda con diversas cúpulas de presión. Entre los pozos $\mathrm{B} 3$ y $\mathrm{C} 1$ hay un canal claramente excavado (Figura 22) y algunos conos de derrubios de pozos ( $\mathrm{Fi}$ gura 23). A partir de C2 se inicia un tramo acuático, natural estrecho y profundo, Lo Largo, (Figura 24) que no llega a superar los 2 metros de profundidad. A partir de D1 se amplía la galería y sube el suelo por hundimiento de la bóveda, especialmente en los sectores D4, D5 y D6 (Figura 25).

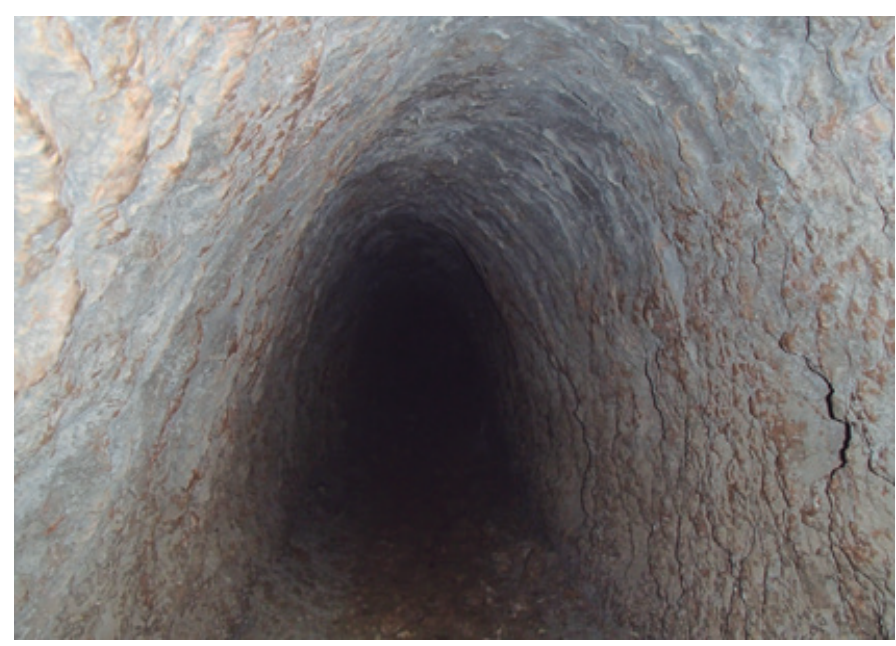

Figura 21. Galería romana.

Figure 21. Roman gallery.

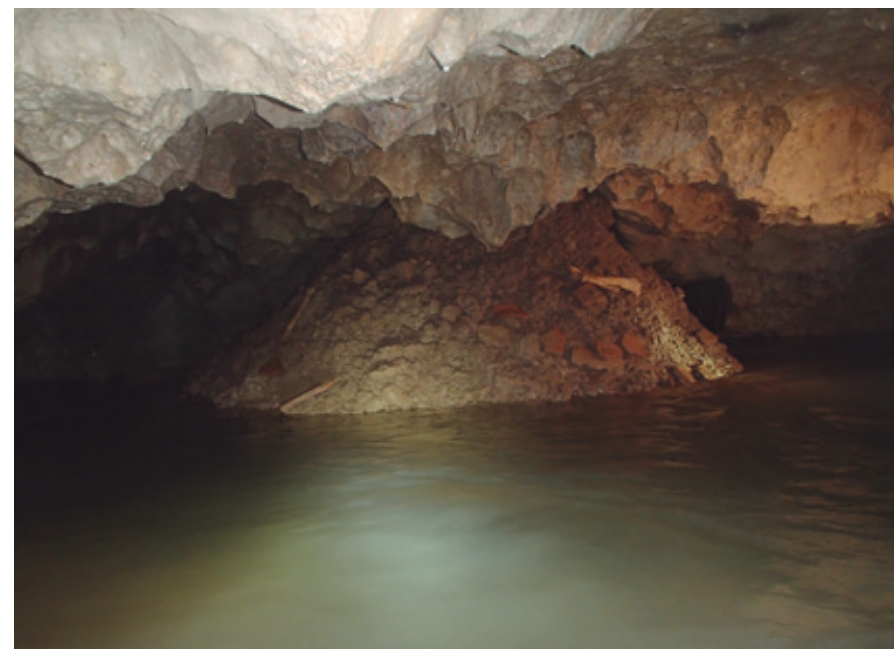

Figura 23. Cono de derrubios del pozo B3.

Figure 23. Debris cone of $B$ well.
Más adelante, pasado un nuevo tramo acuático, se llega a una zona con inscripciones sobre el barro (denominada Soteles) y la planta se hace laberíntica, con galerías laterales de baja altura y techos planos.

El conducto principal lleva primero a una nueva zona acuática, en forma de $L$, que muestra también con un claro nivel de aguas máximas y un depósito arcilloso de fondo con abundantes inscripciones (Figura 26). Este conducto y una gatera lateral llevan a una cámara, el Santuario, conocida por la presencia de diversas figuritas en barro, incluida la denominada Carisius (Figura 27).

A la galería principal, además de la de acceso, acceden tres galerías laterales relativamente secas, denominadas dos de ellas por inscripciones (Caius Magius, Pipio) y la tercera por situarse bajo los edificios de termas. Su acceso es relativamente complicado y sus finales penetrables son bajos y laberínticos.

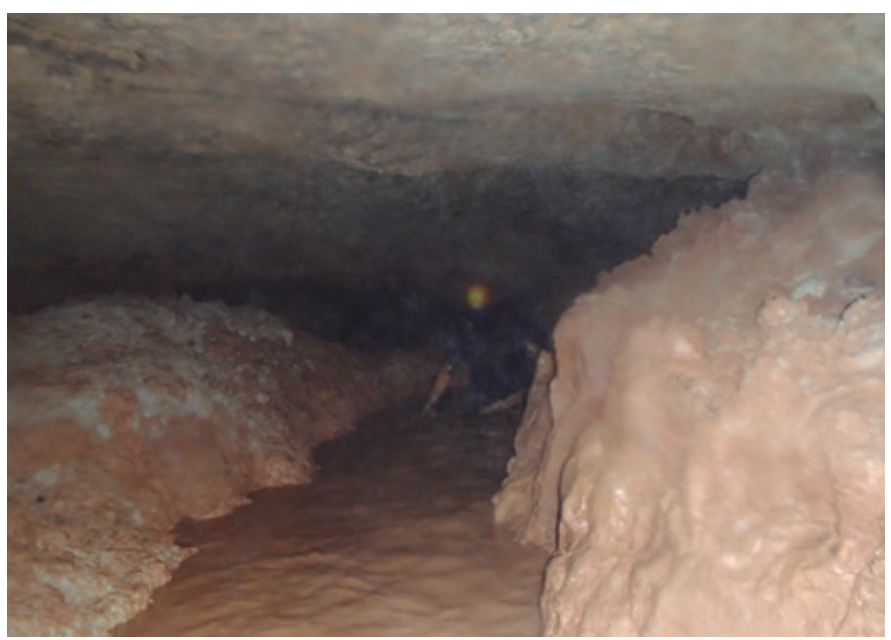

Figura 22. Canal excavado en las cercanías de B3.

Figure 22. Channel excavated near B3.

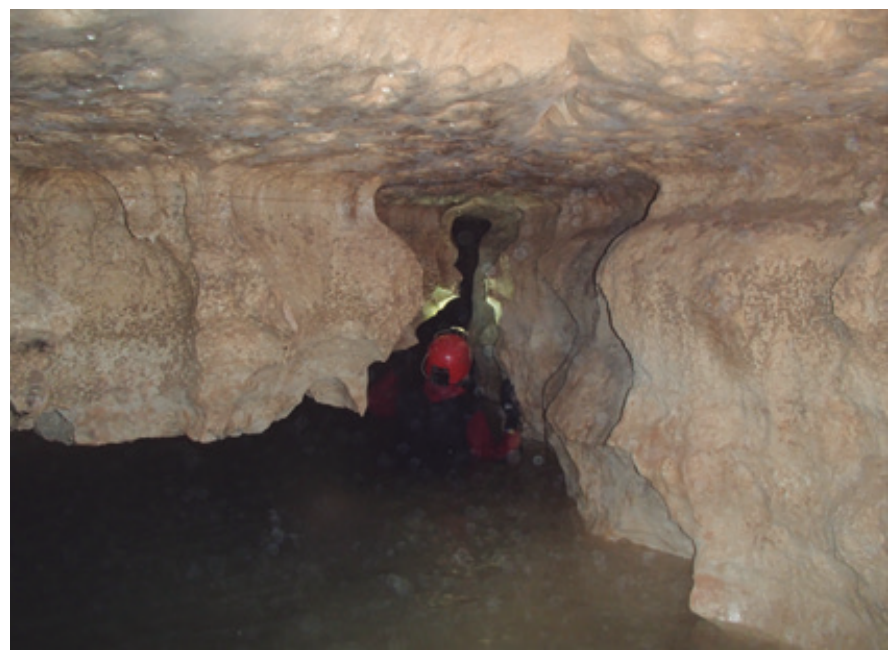

Figura 24. Lo Largo: Muesca característica a techo.

Figure 24. In the "Lo Largo": characteristic roof notch. 


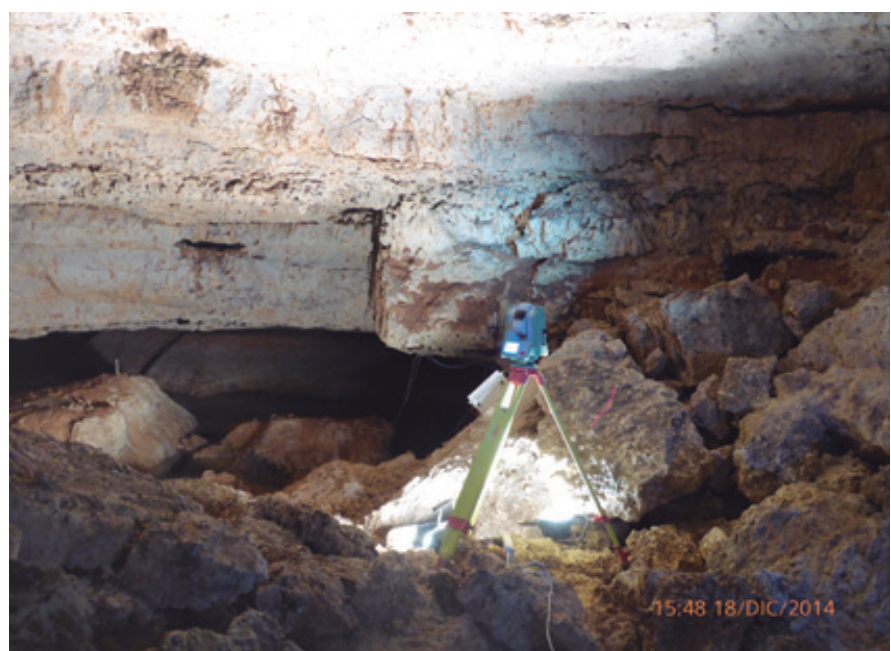

Figura 25. Hundimientos de techo en zona D4-D6.

Figure 25. Roof subsidence in zone D4-D6.

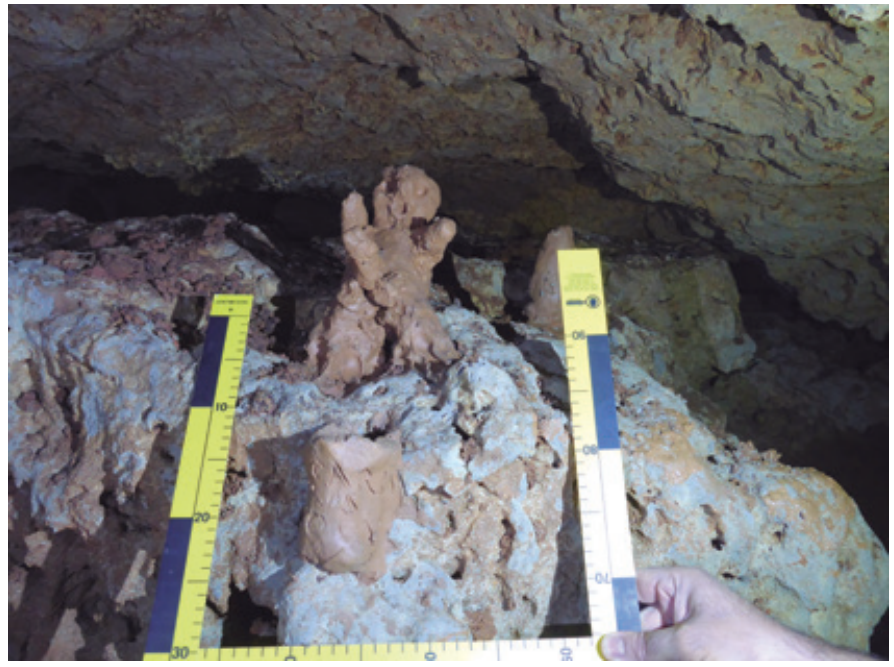

Figura 27. Figura votiva de Carisius. Altura aproximada. $10 \mathrm{~cm}$.

Figure 27. Carisius votive figure. Approximate height: $10 \mathrm{~cm}$.

La galería Caius Magius tiene un primer tramo acuático y algún grafiti (Figura 28). Después, se pasa, bien por un sifón o por una gatera, a una galería estrecha y de poca altura, de tipo reticulado, cuya base es un relleno arcilloso, localmente en proceso de subsidencia. Se dirige hacia el exteriory algunos indicios faunísticos sugieren que llega a la superficie. Un pozo solitario E-1 accede a su zona final.

La galería Pipio, prácticamente fuera del agua, tiene una zona inicial también relativamente amplia, la Sala grande, a la que llega un pozo reprofundizado, que se estrecha en una zona con estalactitas de tipo straw (macarrones) y pequeñas estalagmitas. En la sala e inicio de esta galería se observan restos de carbón vegetal, cáscaras de caracoles y huesos de aves.

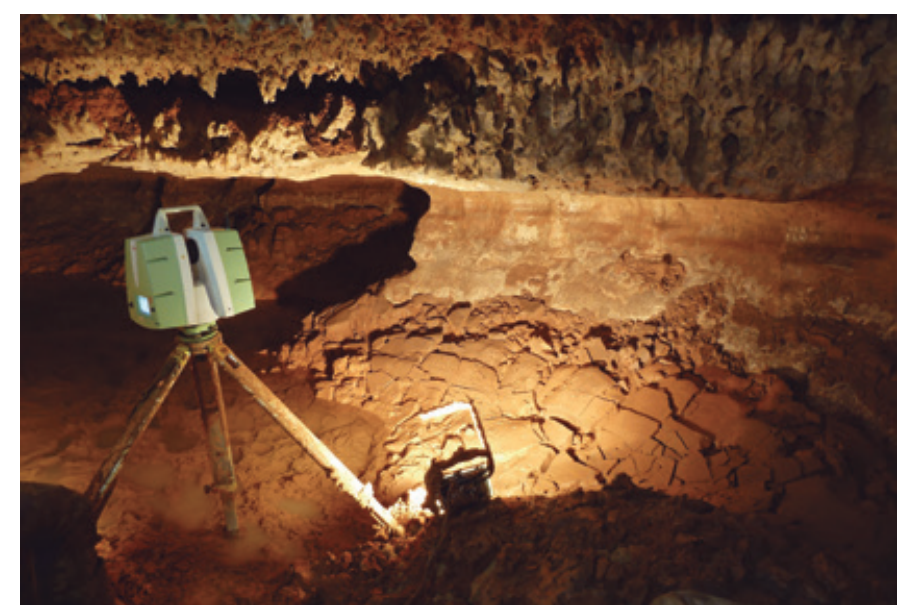

Figura 26. Señal de nivel y depósito de barro con inscripciones en zona Fabricivs.

Figure 26. Level signal and mud deposit with inscriptions in the Fabricivs zone.

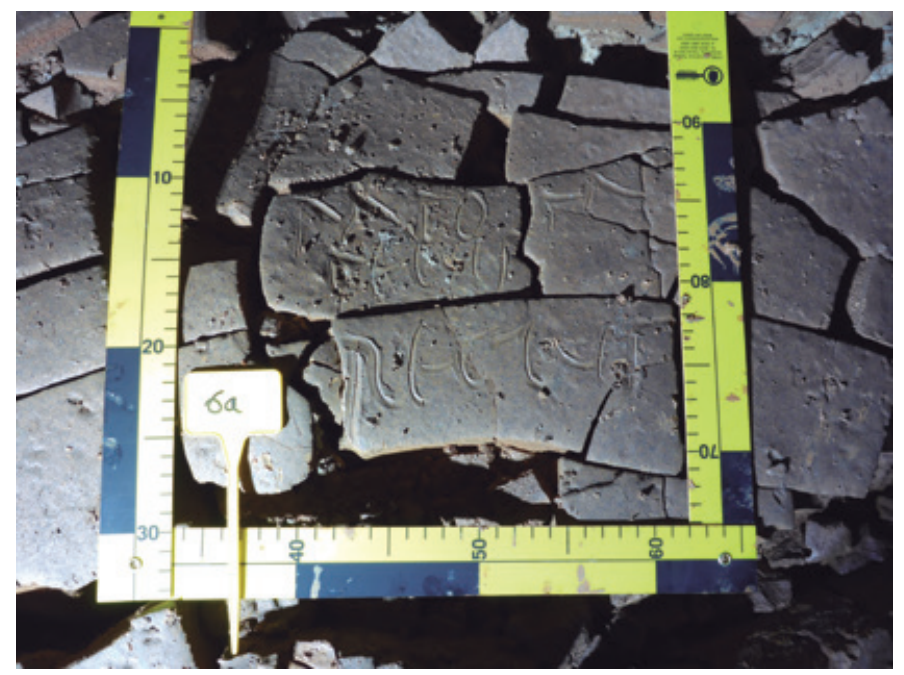

Figura 28. Inscripción en galería Caius Magius.

Figure 28. Inscription in the Caius Magius gallery.

Luego continua por una retícula de galerías bajas y relativamente anchas sobre una capa de sedimentos en fase de subsidencia parcial. A su tramo final, donde se encuentran abundantes planorbis en la roca, llega otro pozo solitario (F2).

La galería Termas tiene un arranque algo complicado y es similar a los finales de las otras dos galerías. Tiene una zona con concreciones sobre la arcilla y crecimiento de cristales de calcita de unos centímetros.

En su conjunto, la cavidad tiene un claro control estructural, por el diaclasado que sugieren las direcciones de la periferia del cerro. Algunas de éstas se observan en el techo de algunos tramos de la galería principal.

La cavidad es básicamente horizontal y no hay indicios de conexión con el nivel calcáreo inferior P1, dado 


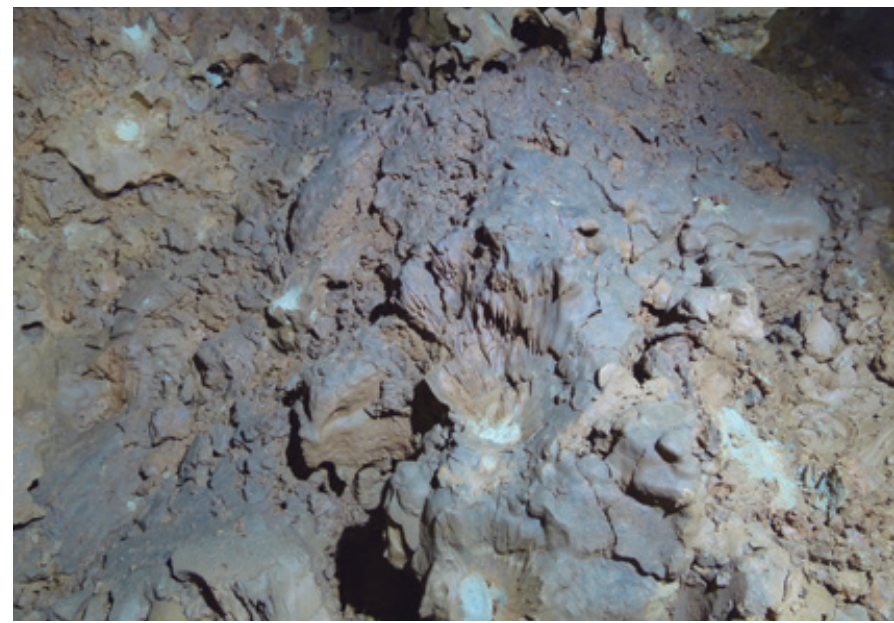

Figura 29. Conulita in situ en zona Soteles.

Figure 29. Conulite in situ. Soteles zone.

que el estrato limoso ha actuado como nivel de base de la karstificación. Aparentemente, la fase inicial se generó en condiciones de un relieve poco enérgico en una serie estratigráfica de poco espesor. Además, en el sistema, como muestra la topografía de la Figura 16 , se observa la existencia de dos tipos de secciones diferentes, pero siempre de reducidas dimensiones. En la galería principal, especialmente en el tramo central, domina una sección de tipo cañón que en algún punto sugiere una morfología en "cerradura". En otras zonas domina una sección amplia, ovalada, de poca altura y mucha mayor anchura en una planta de tipo reticulado.

El cañón principal podría relacionarse con un flujo subterráneo procedente, probablemente, por razones topográficas, de la cordillera Ibérica, antes que se produjera el aislamiento del cerro. En los acantilados próximos a Huerta del Rey se observan abundantes cavidades que pudieran también relacionarse con esta fase. Solo hay un punto, en una confluencia de galerías, se han encontrado indicios de huellas de corriente con una longitud aproximada de $6 \mathrm{~cm}$.

Ya una vez aislado el cerro, se produjo una segunda fase de karstificación, por el agua de recarga local, en condiciones de estancamiento de agua en las galerías preexistentes. Esta fase parece ser responsable de las acanaladuras muy características que se observan a techo de algunos tramos como Lo Largo.

Un importante volumen de sedimento fino, bloques desprendidos del techo, algunos espeleotemas y diversos artefactos arqueológicos forman el relleno de la cavidad. No es fácil conocer la profundidad total de estos. En Lo Largo, donde rara vez se alcanzan 2,5 metros de profundidad de agua, a los que hay que sumar un máximo de 1,5 metros aéreos.

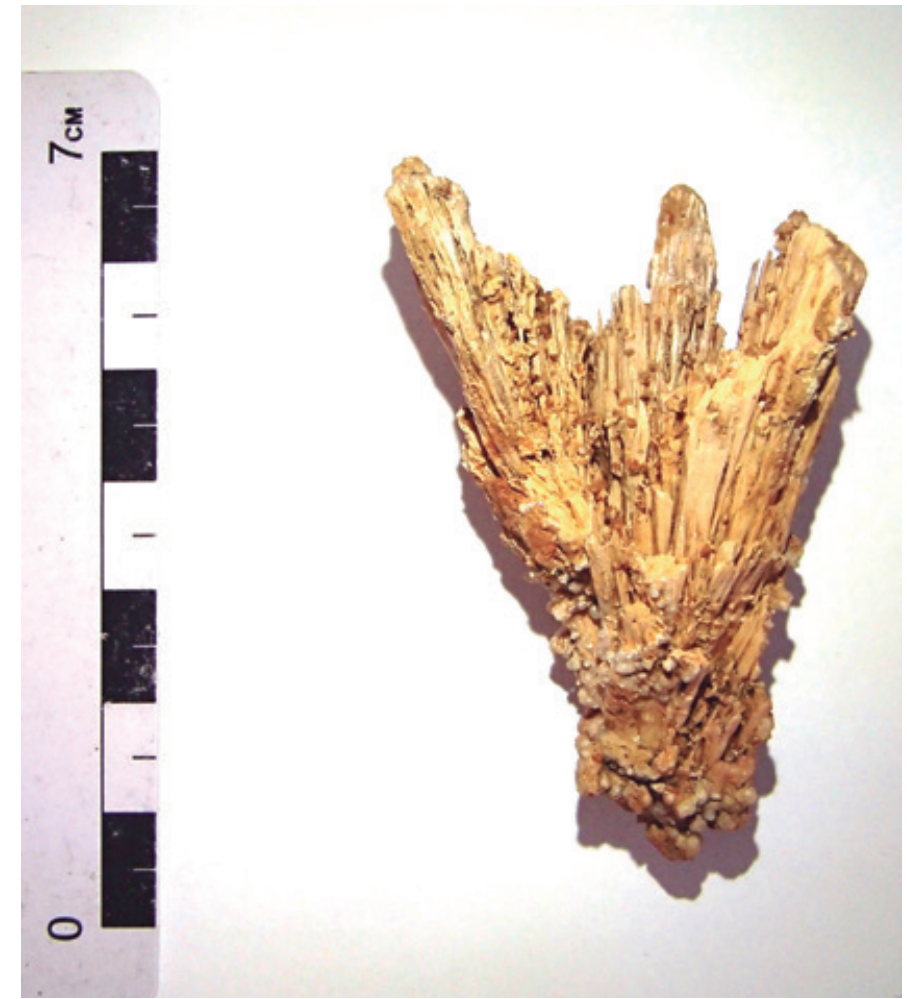

Figura 30. Conulita.

Figura 30. Conulite.

Sorprende la escasez y el poco desarrollo de los espeleotemas en la cavidad, que son muy puntuales. Hay algunas estalactitas tipo straw (macarrones) asociadas a pequeñas estalagmitas, de unos $10 \mathrm{~cm}$ de altura, en el inicio de la galería Pipio, junto con algunas banderas y coladas parietales en la galería principal y en la de Termas. También hay algunos suelos estalagmíticos, de espesor milimétrico, sobre los rellenos arcillosos. Una singularidad es la formación de espeleotemas tipo conulita con crecimiento de cristales en la masa de relleno del suelo y asociables a puntos de goteo singular (Figuras 29 y 30 ). Un difractograma realizado en un equipo para polvo Bruker D8 Advance (Billerica, Massachusetts, Estados Unidos) en configuración Bragg-Brentano $\theta-2 \theta$, trabajando con radiación de rayos-X Cu Ka1 $(\lambda=1.54056 \AA$ ) y con detector PSD Lynx-eye, muestra que se trata de cristales de calcita.

Solo una parte de la cavidad, especialmente en la zona de los pozos D4-D6 y una parte del Santuario presenta bloques de caída cenital. Por el contrario, prácticamente toda la cavidad alberga importantes depósitos de material fino, que complica mucho el trabajo de interior, que se pueden clasificar, por el color, en tres tipos. Por un lado, localmente en el techo de la cueva aparecen bolsadas de terra rossa, de evidente color rojo intenso (2,5YR 5/6 en seco y 10R4/6 en húmedo) 


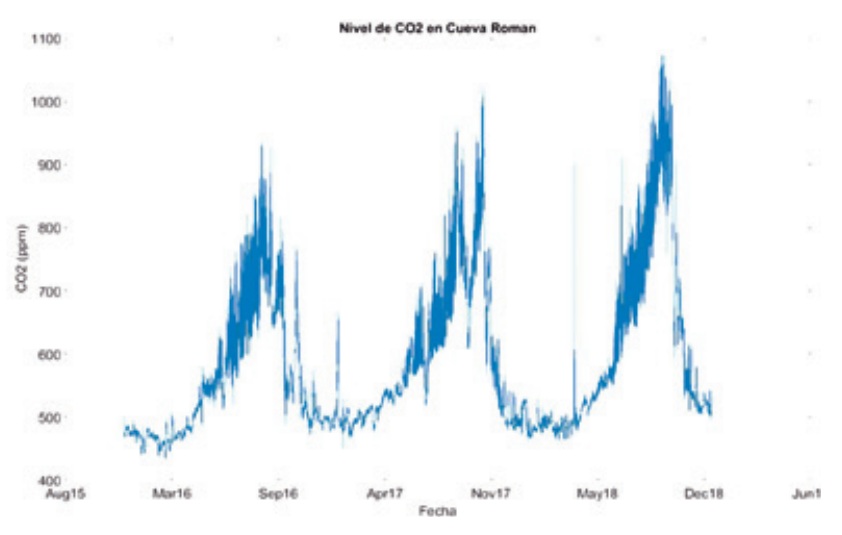

Figura 31. Evolución de $\mathrm{CO}_{2}$ en ERPA de enero 2016 a diciembre 2018. Figure 31. Evolution of $\mathrm{CO}_{2}$ in ERPA from January 2016 to December 2018.

con fractura poliédrica, slickensidesy dendritas. Es de tacto fino y muy pegajoso en húmedo. Por otro lado, numerosos conductos subverticales de tipo radiciforme, aparecen también rellenos de este material. EI material limoso del nivel de base, normalmente bloques caídos, genera por pisoteo un barro fino de color blanquecino (2,5Y 9/1 en seco). Se puede considerar caliza descarbonatada en el interior y posiblemente puede contener caolín, heredado de la $\mathrm{fm}$. Utrillas.

El depósito más habitual es un fango de color pardo (5YR 6/4 en seco; 5YR 4/4 en húmedo) que recubre parcialmente la parte inferior de la galería inundada, como hasta un metro del nivel actual del agua. Muy pegajoso y de tacto fino. Fue profusamente utilizado en época romana para la realización de grafitis que, en su mayoría, están hoy por encima del agua. Este material parece una mezcla de los dos depósitos anteriores, más aportaciones de carbón vegetal de antorchas y basura orgánica. Es difícil conocer el espesor en la base de la cavidad, pero en los laterales en pendiente no supera generalmente los $10 \mathrm{~cm}$. En muchas partes está cuarteado y desliza hacia el agua, comprometiendo la pervivencia de los grafitis realizados, aparentemente, antes de su fractura.

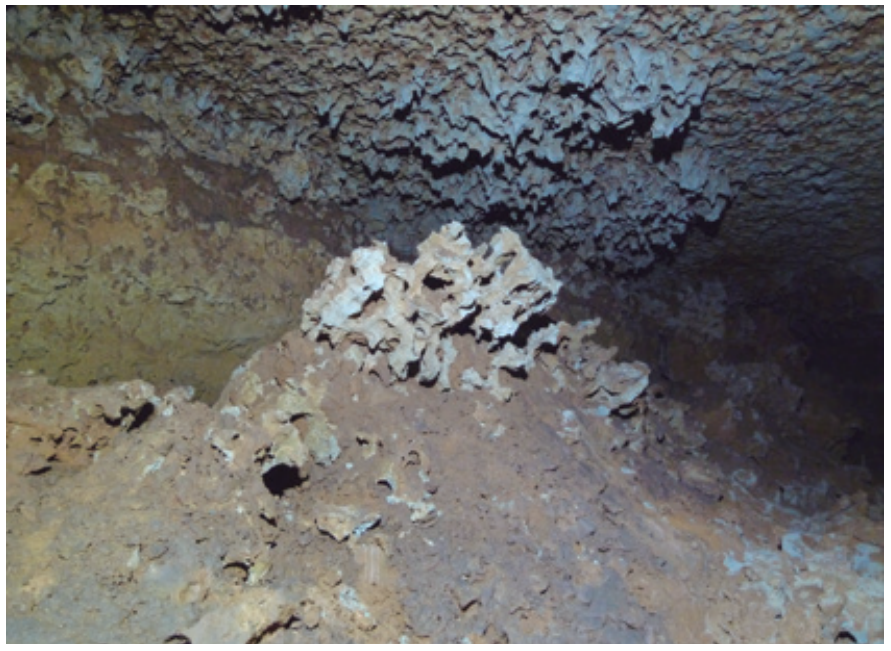

Figura 32. Corrosión de la roca en la zona Soteles.

Figure 32. Corrosion of the rock at the Soteles area.

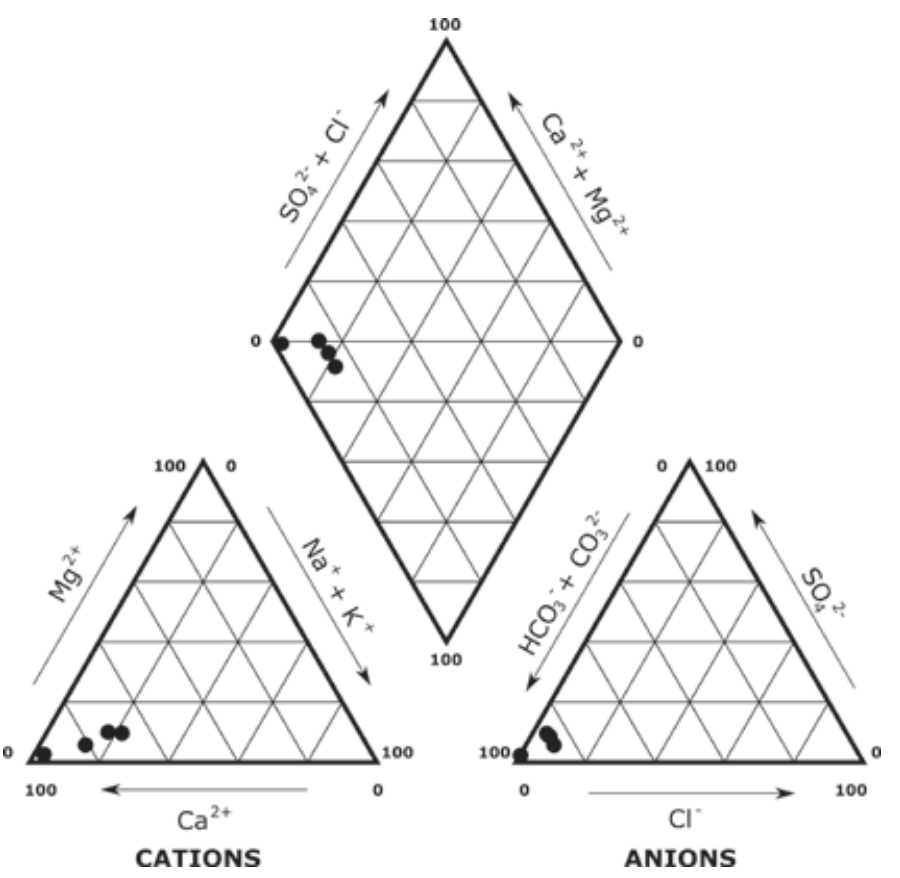

Figura 33. Diagrama de Piper de aguas subterráneas de Clunia.

Figure 33. Piper diagram of groundwater at Clunia.

\begin{tabular}{|c|c|c|c|c|c|c|c|c|c|c|c|c|c|c|}
\hline Muestra & $\operatorname{tmp}$ & CE campo & CE lab & $\mathrm{pH}$ & Alcalinidad & Dureza & $\mathrm{HCO}_{3}{ }^{-}$ & $\mathrm{Cl}^{-}$ & $\mathrm{SO}_{4}{ }^{2-}$ & $\mathrm{NO}_{3}^{-}$ & $\mathrm{Na}^{+}$ & $\mathrm{K}^{+}$ & $\mathrm{Ca}^{2+}$ & $\mathrm{Mg}^{2+}$ \\
\hline & oc & $\mathrm{microS} / \mathrm{cm} 25^{\circ} \mathrm{C}$ & $\mathrm{microS} / \mathrm{cm} 20^{\circ} \mathrm{C}$ & $20 \circ \mathrm{C}$ & $\mathrm{mg} / \mathrm{l}$ & $\mathrm{mg} / \mathrm{l}$ & $\mathrm{mg} / \mathrm{l}$ & $\mathrm{mg} / \mathrm{l}$ & $\mathrm{mg} / \mathrm{l}$ & $\mathrm{mg} / \mathrm{l}$ & $\mathrm{mg} / \mathrm{l}$ & $\mathrm{mg} / \mathrm{l}$ & $\mathrm{mg} / \mathrm{l}$ & $\mathrm{mg} / \mathrm{l}$ \\
\hline & & & & & & & & & & & & & & \\
\hline Cueva Román & 12,6 & 207 & 208 & 8,1 & 84 & 104 & 102 & $<10$ & $<10$ & 24,6 & $<10$ & 8 & 35,8 & 2,4 \\
\hline PozotermasForo & 12,3 & 240 & 220 & 7,9 & 90 & 101 & 110 & $<10$ & $<10$ & 20,7 & $<10$ & 12,1 & 34,9 & 2,6 \\
\hline FteTeatro & 14,1 & 255 & 229 & 7,8 & 88 & 120 & 108 & $<10$ & $<10$ & 31,8 & $<10$ & 4,9 & 42,7 & 1,8 \\
\hline Fte3 casa excav & 10,9 & 575 & 452 & 7 & 268 & 292 & 327 & $<10$ & $\mid<10$ & $<2$ & $<10$ & 3,2 & 111 & 2,2 \\
\hline
\end{tabular}

Tabla 1. Conductividad eléctrica (CE), temperatura y análisis químico de diversos puntos de agua en Clunia. Alcalinidad y dureza como carbonato cálcico.

Table 1. Electrical conductivity (EC), temperature and chemical analysis of various water points in Clunia. Alkalinity and hardness as calcium carbonate. 


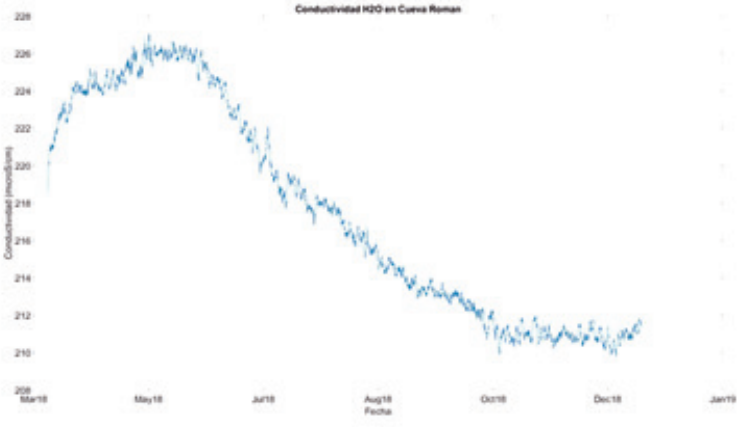

Figura 34. Evolución de la conductividad eléctrica del acuífero de Clunia, entre marzo y diciembre de 2018.

Figure 34. Evolution of the electrical conductivity of the Clunia aquifer, between March and December 2018.

\section{Temperatura del aire y del agua de la cavidad, hume- dad relativa y $\mathrm{CO}_{2}$}

El seguimiento de diversos parámetros meteorológicos en la cavidad es de interés para la preservación de los grafitis y las figuras de barro. Como se ha señalado, la instalación de la ERPA precedió a la apertura del pozo D6. En ésta, entre 2014 y 2019 , las temperaturas de agua $\left(11,7^{\circ} \mathrm{C}\right)$ y aire $\left(12,8^{\circ} \mathrm{C}\right)$, y la humedad relativa $(100 \%)$ se han mantenido constantes, indicando que la estación está en una zona de atmósfera estancada y que funciona adecuadamente el sistema de sellado del pozo D6. Estos resultados son compatibles con los obtenidos en varios sensores de la marca HOBO que estuvieron registrando entre 2003 y 2006 . La excepción es el sensor situado en la intersección de la galería de entrada y Caius Magius cuya variabilidad, casi $10^{\circ} \mathrm{C}$, indica la existencia de una corriente de aire entre ambas galerías conectadas con el exterior. Por el contrario, el interior de la cavidad funciona en plan estanco y, por tanto, no parece existir otra salida hacia el exterior.

Más variabilidad presenta la concentración de $\mathrm{CO}_{2}$ (Figura 31). Se observan tres ciclos anuales con mínimos invernales y máximos estivales, con una tendencia al alza en los valores extremos así como una clara evolución diaria, con mayor rango en verano que en invierno.

Cueva Román no es una cavidad turística y, como máximo, tiene un acceso de 200 horas persona/año. De hecho, no se reconocen las entradas de trabajo de arqueólogos y miembros de GTE en el registro del $\mathrm{CO}_{2}$ Sin embargo, a diferencia con otras cuevas estudiadas, hay una evidente presencia de materia orgánica desde madera, a restos humanos. Como la

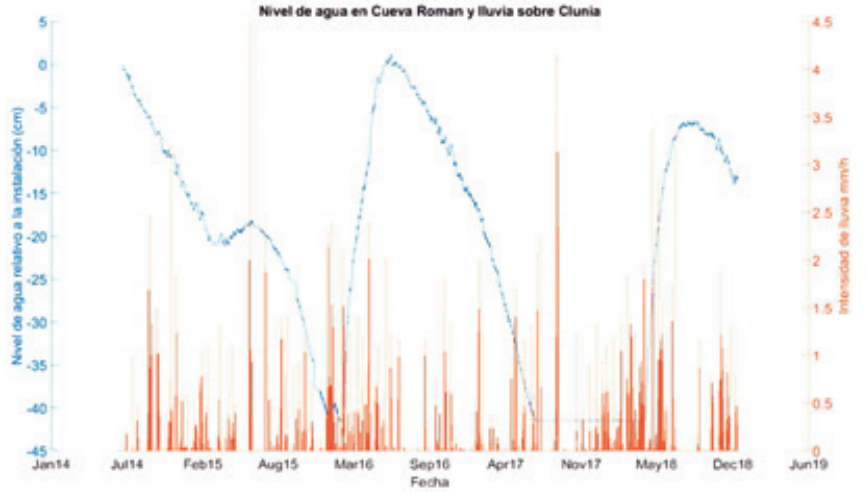

Figura 35. Evolución del nivel freático en la ERPA y precipitación en la EMET desde enero de 2014 a diciembre de 2019. Cota cero de referencia: 990,63 m.s.n.m. Precipitación acumulada cada 6 horas.

Figure 35. Evolution of the water table and precipitation from January 2014 to December 2019. Reference level: 990.63 m.a.s.I. Accumulated rainfall every 6 hours.

actividad microbiana está relacionada con la temperatura y ésta es constante en el interior, se puede sugerir que el incremento de $\mathrm{CO}_{2}$ veraniego y las variaciones diarias tienen su origen en los procesos de ventilación y transferencia entre los diversos tipos de porosidad, similares a los señalados por Baldini et al. (2006), Serrano-Ortiz et al. (2010) y Cuezva et al. (2011).

El rango anual y la evolución de resultados son similares a los presentados para Ojo Guareña por García Antón et al. (2017). No obstante, por ahora, no hay explicación para los picos singulares del invierno de 2016 y la primavera de 2018, ni para la tendencia general al alza. Este aspecto, como otros, necesita un estudio más prolongado.

\section{Hidroquímica}

El 22 de noviembre de 2014 se realizaron cuatro muestreos de agua para análisis iónico en la confluencia de las galerías principal y Caivs Magius, en la pequeña fuente del teatro $\left(\mathrm{Q}=0,987 \mathrm{~m}^{3} / \mathrm{día}\right)$, en el pozo de las termas del foro y en uno de los manantiales de abastecimiento de la casa de la excavación. Los resultados se presentan en la Tabla 1.

Los análisis indican que, en las muestras de interior, el nivel iónico está por debajo de lo habitual en aguas kársticas. Destaca la ausencia de cloruros y sulfatos, así como el bajo nivel de magnesio. Los resultados pueden también relacionarse con el elevado aspecto de corrosión que tiene la caliza en algunas zonas de la cavidad (Figura 32), así como la pobreza de espeleotemas. Por otro lado, en estas aguas son altos los niveles de nitrato y potasio que, en otras condiciones se atribuirían a abonados agrícolas, pero la zona 
de recarga está sin cultivo desde hace más de dos décadas. Esto, y la inusual relación $\mathrm{Na}^{+} / \mathrm{K}^{+}$, sugieren el efecto de restos arqueológicos orgánicos.

El agua de rezumes periféricos, como las fuentes de la casa de la excavación, que han percolado por el coluvión/escombrera de la ladera, presentan valores más altos de CE y alcalinidad que el agua del interior. Parece probable una aportación iónica de las margas intermedias.

El diagrama de Piper (Figura 33), muestra una clara similitud entre las cuatro muestras de agua, aunque se esboza una pequeña tendencia lineal en el triángulo catiónico. La aplicación del programa de especiación WATEQ4F presenta una insaturación general en todas los minerales (SI negativo), excepto en una muy leve saturación en calcita en la muestra del interior de cueva Román.

La conductividad eléctrica (Figura 34) presenta una ligera oscilación temporal. La corta serie temporal registrada insinúa la existencia de una relación inversa entre ascenso de nivel y descenso de la CE que, a tra- vés del menor contenido iónico del agua de recarga sugiere, una vez más, un alto grado de descarbonatación de la montera.

\section{Evolución del nivel freático}

La existencia de oscilaciones de nivel de agua de la cavidad era conocida por los espeleólogos del GER, desde 1980. La figura 35 presenta la evolución del mismo registrada por la ERPA en relación con la lluvia a partir de los datos de la EMET. Desde enero de 2014 a diciembre de 2019 , se han observado dos oscilaciones del orden de $0,5 \mathrm{~m}$ a partir de una cota referencial de 990,63 m s.n.m.

Durante la sequía del otoño de 2017 y el inicio de 2018, el nivel quedó por debajo del mínimo del sensor que tuvo que ser reposicionado. Los descensos son tan rectilíneos que se sospechó el efecto de un importante bombeo, de ubicación desconocida, especialmente por el retraso que se observaba tras el inicio de las lluvias de la primavera de 2018. Una detallada inspección te-

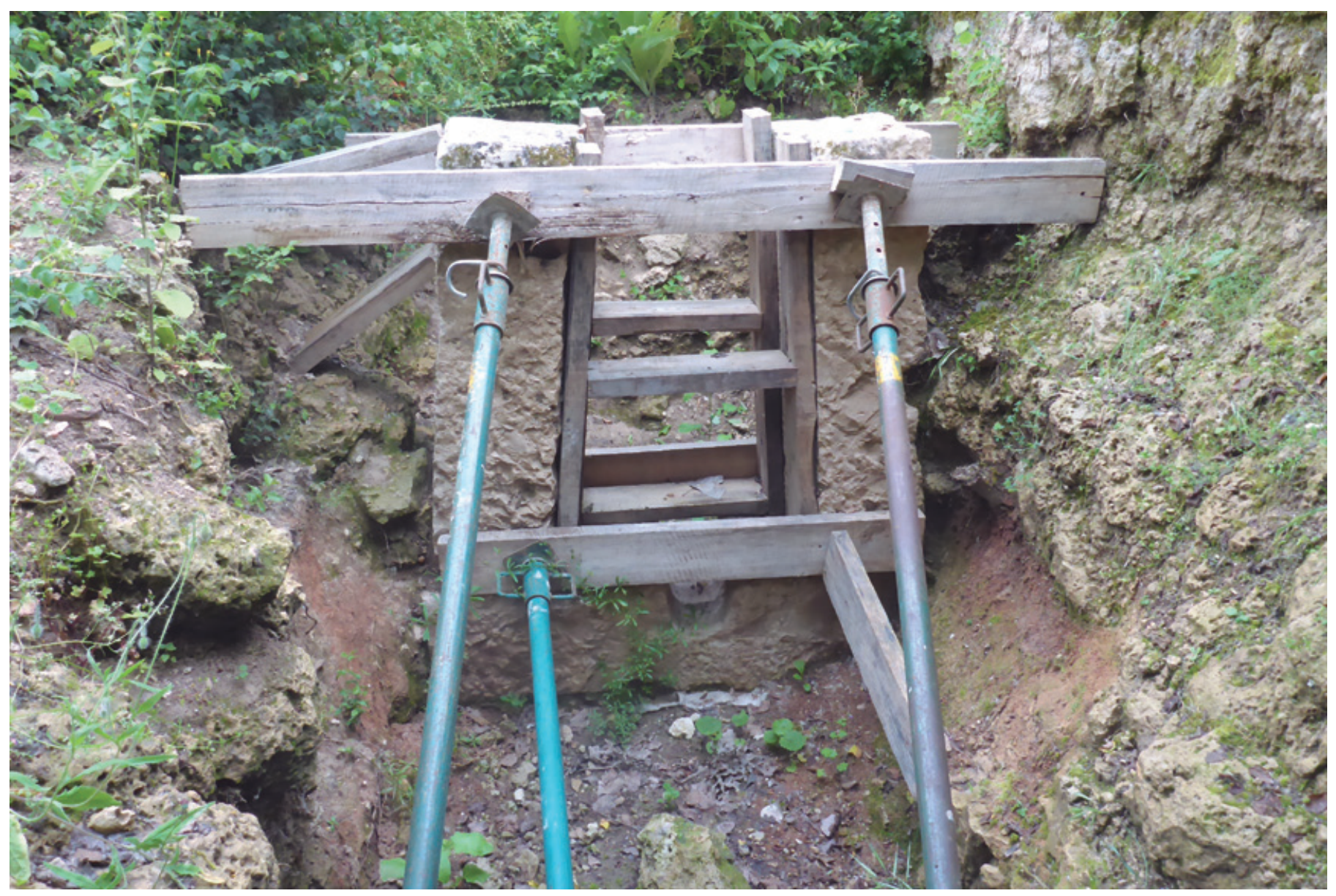

Figura 36. Compuerta, con un canal de aguas continuas, en la boca de Cueva Román.

Figure 36. Gate, with a continuous water channel, at the mouth of the Roman Cave. 
rritorial descartó la influencia humana. Pero posteriormente, el nivel interior tuvo una espectacular recuperación. Desde el otoño de 2018 ha emprendido un nuevo descenso. Evidentemente es todavía pronto para realizar un análisis sistémico sobre un modelo conceptual, de recarga superficial y descarga periférico, que inicialmente parece sencillo y que indica un comportamiento lento y la existencia de fuertes estiajes.

\section{La captación de agua subterránea por la Clunia roma- na y sus problemas}

Como ya se ha señalado, el acuífero y la cavidad fueron conocidos y utilizados durante la época romana, tema que evidentemente ha llamado la atención de arqueólogos e historiadores. Se han señalado diversas funciones para la cavidad bajo Clunia como centro de fangoterapia y santuario priápico (GER, 1986b; Palol y Vilella, 1986, 1988 b; Palol, 1994; Cuesta, 2011, 2012). Con independencia de lo señalado, una importante función del acuífero bajo Clunia era el abastecimiento de agua a la ciudad. Hay que señalar que no se conocen restos de acueducto o sifón.

Para su abastecimiento, en la ciudad romana se abrieron diversos pozos, hoy todos cegados aunque alguno todavía estaba en servicio en el siglo XIX. Se conocen 19 que llegaron a las galerías kársticas conocidas. Sus conos de derrubios han sido radiolocalizados de modo que se ha relacionado con bastante precisión la topografía subterránea con la superficial. Esto ha permitido poner en relación determinados edificios con sus pozos como es el caso de las termas de los Arcos I y II. Los escombros de base de algunos de los pozos cegados, B3, C3, C4, se encuentran actualmente en contacto con el agua pero los de otros, C1, D4, D5 y D6, hoy se localizan por encima del nivel freático actual, dentro de la cavidad. Además, se observan trabajos de reexcavación en las bases de algunos pozos e incluso en algún tramo del cauce subterráneo.

No es posible saber cuántos pozos se abrieron hasta el freático, sin tener conexión con cavidades. A partir de los trabajos arqueológicos se conocen cuatro. Sólo por el denominado de las termas del foro, a sureste de la ermita de la Virgen de Castro, se accede hoy al agua (991,2 m s.n.m en noviembre de 2014).

Hay que considerar la alcantarilla del teatro romano y cueva Román como obras romanas de captación. La primera es una obra de eliminación de agua molesta. Debió aflorar durante las obras del graderío y exigió cierta maestría en las obras de drenaje. Dado que la construcción de este coincide con el abandono del primer edificio de termas, es posible que el drenaje afectara al abastecimiento de agua de éstas.
Como se ha señalado, el tramo inicial de cueva Román es una inacabada galería rectilínea excavada con la típica sección ovalada y huecos para lucernas (Figura 21). Intercepta dos bocas de pozos A1 y A2 y parece dirigirse hacia B2. Pero el hallazgo, en su momento, de una galería natural, cuyo relleno también se ve parcialmente excavado, permitió el acceso a la cavidad natural. Las características de esta parte artificial y la existencia de una compuerta (Figura 36) junto a la actual boca indican que se trataba de una galería de captación de agua. La compuerta, excavada por B. Taracena en 1930 (Taracena et al., 1947), tiene una gorronera, y un pequeño canal inferior para dejar pasar un pequeño caudal constante a compuerta cerrada. El punto inferior de canalículo de la compuerta se encuentra a 991,98 ms.n.m.

Es evidente que, en época romana, la extracción de agua del acuífero por los pozos, mediante esfuerzo humano o animal, debería ser limitada, incluso en el denominado de Los Cangilones, junto al edificio Termas II. Sin duda era mucho mayor el efecto de vaciado continuo del acuífero tanto por el drenaje del teatro como por cueva Román.

Es importante reseñar que alguno de los grafitis se encuentra hoy por debajo del agua, sugiriendo que el nivel estaba más bajo cuando se realizaron. Por otro lado, no parece probable, por las condiciones de la cavidad y los medios de la época, que el conjunto de la cavidad fuera explorado en su totalidad en época romana.

De cualquier manera, es evidente que bien por causas naturales y/o por la extracción antrópica, los niveles de agua bajaron, obligando a descender por los pozos a grupos de trabajadores especializados que excavaron los canales ya reseñados, profundizaron las bases de los pozos y dejaron huellas de las tachuelas de caligae. Estos operarios quizás estuvieran relacionados con otros clunienses cuyas epigrafías aparecen en los distritos mineros de Cáparra (Gómez-Pantoja, 1999), Linares-La Carolina (Arboledas, 2009) y norte de Portugal (Santos-Yanguas, 1979).

Desde luego, también bajaron a la cavidad personas que sabían escribir y que dejaron los abundantes e interesantes grafitis. Es posible que tuvieran varias motivaciones, pero ciertamente una crisis hídrica es una buena razón. El grafiti de los quattorviri parece un buen ejemplo de la necesidad que tuvo una magistratura asociada con la gestión del agua en descender y dejar testimonio de su presencia, a la cavidad (Cuesta, 2012).

No es fácil establecer una relación entre los niveles actuales de agua y los existentes en la época romana en Clunia, que duró al menos cuatro siglos. Desde luego, el nivel piezométrico debió de variar tanto por razones climáticas como de explotación. La información 
climática cercana sobre el periodo romano es escasa. El estudio sintético de McCormick et al., (2012) señala un "óptimo romano", estable y relativamente cálido y húmedo entre 100 AC y 200 DC, seguido de un enfriamiento posterior. Para zonas relativamente próximas, Martín-Chivelet et al., (2011), a partir de espeleotemas en la provincia de Burgos, Kaite, cueva del Cobre y cueva Mayor, indican un enfriamiento en el primer siglo DC, un breve recalentamiento en el segundo y un largo enfriamiento hasta el sexto. Evidentemente, esta información es solo indicativa, dado que no registra episodios cortos y agudos de sequía. Visto el comportamiento actual del acuífero, parece que es muy sensible a pequeñas oscilaciones en la lluvia.

\section{Conclusiones}

A lo largo de los últimos años, se ha profundizado en el conocimiento del endokarst de Clunia y su patrimonio hidroarqueológico. Es evidente que la existencia bajo su cerro de un modesto acuífero kárstico, libre y colgado, tuvo una relación directa con la ciudad romana. Es posible, incluso, que fuera una de las razones para la creación de la misma en este lugar. Desde luego fue su abastecimiento de agua básico dado que no se conoce ningún acueducto que realizara esta función.

La ciudad se suministró a partir de una galería y unos pozos excavados a mano. Parte de estos alcanzaron una cavidad natural. El descenso de niveles de agua en el acuífero y la cavidad, bien por causas naturales o por el drenaje relacionado con las obras del teatro, obligó a la reprofundización de algunos pozos $y$ al descenso de diversas personas que dejaron diversos graffitisy algunas estatuillas de barro.

El trabajo realizado desde 2004 por el GTE ha permitido radiolocalizar los pozos, resituar la topografía del GER sobre la imagen georeferenciada de la ciudad y escanear en 3D partes importantes de la cavidad y de detalles arqueológicos. Se han estudiado diversos detalles geológicos de este endokarst, controlado por la red local de diaclasas y desarrollado en dos fases, antes y después del aislamiento del cerro. Se ha constatado que el desarrollo de espeleotemas es muy limitado mientras que los depósitos de sedimentos detríticos son importantes.

La instalación de la ERPA en el interior, en la zona de los pozos D4-D6, permite observar que no ha habido un efecto apreciable, en temperatura y humedad relativa, por la apertura del pozo D6. El interior de la cueva es una zona estancada, de modo que la evolución de los niveles de $\mathrm{CO}_{2}$ en la zona interior de la cavidad sigue un doble esquema evolutivo, diario y anual que podría relacionarse con la ventilación y el trans- porte de este gas entre la cavidad y la matriz porosa de la roca. La relación entre la lluvia y el nivel freático es relativamente intensa, acusa claramente los periodos de sequía pero tiene un retraso del orden de unos dos meses de respuesta a la lluvia.

Hay suficientes evidencias para suponer que, en época romana, la combinación de los fenómenos atmosféricos naturales y el efecto de la extracción, pudieron afectar de manera notable el abastecimiento del agua en la Colonia Clunia Sulpicia.

\section{Agradecimientos}

Se agradece la financiación parcial de la Diputación provincial de Burgos (ayudas 2014/0360, 2015/0445) y la financiación parcial del proyecto DGA_T45-17R. Reconocemos también el trabajo y compañía de Clara Valladolid Beatriz Rubio, Mónica Gorostiza y Gerardo Martínez del Equipo de Investigación de Clunia. José Secorún de la productora Rumbo Sur, nos grabó y acompañó en varias entradas. Agradecemos a Pablo Martín Ramos la realización del difractograma de la conulita. Agradecer la ayuda sobre el terreno de Pedro Niño y Jaime Briongos. Al Grupo de Espeleología Ribereño hay que reconocerle su buen trabajo de topografía.

\section{Referencias}

Arboledas, L. 2009. La epigrafía minera romana del distrito de Linares-La Carolina (Jaén). Anales de Arqueología Cordobesa, 20, 257-278.

Armenteros, I. 1986. Evolución paleogeográfica miocena en el sureste de la Depresión del Duero. Studia Geologica Salmanticensia, XIII: 325-337.

Arnavat, M.G. 1998. Levantamiento espeleológico de la Cova Urbana de Tarragona. Trabajo fin de carrera. UP Cataluña.

Ayuso, N., Cuchí, J.A., Lera, FVillarroel, J.L. 2010. Accurately locating a vertical magnetic dipole buried in a conducting earth IEEE Transactions on Geoscience and Remote Sensing 48 (10), 3676-3685

Baldini, J. U., Baldini, L. M., McDermott, F., Clipson, N. 2006. Carbon dioxide sources, sinks, and spatial variability in shallow temperate zone caves: evidence from Ballynamintra Cave, Ireland. Journal of Cave and Karst Studies, 68(1), 4-11.

Benito-Calvo, A., Pérez-González, A. 2007. Erosion surfaces and Neogene landscape evolution in the NE Duero Basin (north-central Spain). Geomorphology, 88, 226-241.

Calvo, I. 1916. En las ruinas de Clunia. Revista de Archivos Bibliotecas y Museos, 34, 92-113.

Camacho, G. 2014. Clunia: una perspectiva arqueológica. Clío, 40, 17-22. 
Cuesta, M. R. 2011. Cueva Román: Fuente de abastecimiento - Lugar de culto de la Colonia Clunia Sulpicia. En Costa, A., Palahí, L. y Vivó, D. (ed.), Aquae Sacrae. Agua y sacralidad en la antigüedad, Girona, 167-180.

Cuesta, M. R. 2012. Recursos hídricos, sistema kárstico y gestión del agua en la Colonia Clunia Sulpicia. Tesis Doctoral. Universidad Rovira i Virgili - Institut Català d'Arqueologia Clàssica. Tarragona. 377 pp.

Cuezva, S., Fernández-Cortes, A., Benavente, D., Serrano-Ortiz, P., Kowalski, A. S., Sanchez-Moral, S. 2011. Shortterm $\mathrm{CO}_{2}(\mathrm{~g})$ exchange between a shallow karstic cavity and the external atmosphere during summer: Role of the surface soil layer. Atmospheric Environment, 45(7), 14181427.

García Entero, V., Gutiérrez García-Moreno, A., Zarco Martínez, E. (2018). Las canteras de calizas y conglomerado de Espejón (Soria). Evidencias arqueológicas y la documentación escrita. En Gutiérrez Garcia-M., A. and RouiIlard, P. (eds.). Lapidum natura restat... Canteras antiguas de la península ibérica en su contexto (cronología, técnicas y organización de la explotación)/Carrières antiques de la péninsule lbérique dans leur contexte (chronologie, techniques et organisation de I'exploitation), p. 185-196. Institut Català d'Arqueologia Clàssica. Tarragona.

García-Anton, E., Cuezva, S., Fernández-Cortes, A., Álvarez-Gallego, M., Pla, C., Benavente, D., Sánchez-Moral, S. 2017. Abiotic and seasonal control of soil-produced $\mathrm{CO}_{2}$ efflux in karstic ecosystems located in Oceanic and Mediterranean climates. Atmospheric environment, 64, 31-49.

González Díaz, O. 2008. Proyecto de implantación de una red básica mediante técnicas GPS para dar cobertura al yacimiento arqueológico "Clvnia Svlpicia" (Peñalba de Castro, Burgos). Obtención de cartografía a escala 1/500 y realización de un levantamiento gravimétrico de la misma zona, para intentar localizar posibles galerías subterráneas. Topografía y Cartografía, XXIV, 140, 59-64.

Gris, L., Solís, L., Gris, J. 2002. El acueducto romano de Torralba. Caracterización funcional, hidrogeología y aspectos socieoconómicos ligados a su explotación. Alberca, 1, 171-209.

Grupo Espeleológico Ribereño 1986a. La cueva de Román, Clunia. Objeto de una gran obra de ingeniería romana. IX Congreso Internacional de Espeleología, Barcelona, 202-204.

Grupo Espeleológico Ribereño 1986b. Un posible santuario priápico en la cueva de Román, Clunia. IX Congreso Internacional de Espeleología, Barcelona, 205-207.

Grupo Espeleológico Ribereño 1995. Cueva de Román. Clunia. Memoria 1981-1994. Inédito.

Harper, K. 2017. The fate of Rome: Climate, disease, and the end of an empire. Princeton University Press. 440 pp.
Hinojal, V. 1913. Clunia. Boletín de la Sociedad Española de Excursiones. Arte, Arqueología e Historia. Tomo XXI, Madrid, 222-244.

De la Iglesia, M.A., Tuset, F. 2010. Clunia, centro de poder territorial. En Buron, M. (ed), Patrimonio Cultural y Territorio en el Valle del Duero. Junta de Castilla y León, 75-86.

De la Iglesia, M.A., Tuset, F. 2012. Colonia Clunia Sulpicia. Ciudad romana. Diputación de Burgos. Burgos.136 pp.

IGME. 2008. Hoja 347 (Peña Aranda de Duero) del Mapa geológico de España. Escala 1:50.000. 100 p. 1 mapa.

Loperráez, J. 1788. Descripción histórica del Obispado de Osma, con tres disertaciones sobre los sitios de Numancia, Uxama y Clunia. Imprenta Real. Madrid.

López Camacho, B., Bustamante, I., Iglesias, J. A. 2005. El Viaje de Agua (Qanat) de la Fuente Grande de Ocaña (Toledo): Pervivencia de una reliquia hidráulica. Revista de Obras Públicas, (3.451), 43.

Martín-Chivelet, J., Muñoz-García, M. B., Edwards, R. L., Turrero, M. J., Ortega, A. I. 2011. Land surface temperature changes in Northern Iberia since 4000 yr BP, based on $\delta 13 \mathrm{C}$ of speleothems. Global and Planetary Change, 77(1-2), 1-12.

Martínez Jiménez, J. 2013. Aqueducts and Water supply in the towns of Post-Roman Spain (AD 400-1000). Doctoral dissertation, Oxford University, UK. 249 pp.

Martins, M., Meireles, J., Ribeiro, M. D. C. F., Magalhães, F., Braga, C. 2012. The water in the city of Braga from Roman Times to the Modern Age. En Porfyriou, H., Genovese, L. (ed.). Water shapes. Strategie di valorazzione del patrimonio culturale legato all'acqua. Palombi editoriali. Roma. 282 p. pp. 65-80.

Martos, S., Morales, R., Durán, J.J. 2018. El agua subterránea en la historia. De cómo la humanidad se ha abastecido mediante las aguas subterráneas desde el Paleolítico hasta la época de las catedrales góticas. Los libros de la Catarata. Madrid. $142 \mathrm{p}$.

McCormick, M., Büntgen, U., Cane, M. A., Cook, E. R., Harper, K., Huybers, P., Litt, T., Manning, S.W., Mayewski, P.A., More, A.F.M., Nicolussi, K., Tegel, W. 2012. Climate change during and after the Roman Empire: reconstructing the past from scientific and historical evidence. Journal of Interdisciplinary History, 43(2), 169-220.

Millán, J. 2018a. La mina de agua del Alcázar del rey Don Pedro (Carmona, Sevilla). Gota a gota, 15, 5-13.

Millán, J., 2018b. La mina de agua de la Alameda de Alfonso XIII (Carmona, Sevilla). Gota a gota, 16, 68-74

Millán, J., 2019. La mina de agua romana del Cortijo de la Mina o de Acinipo (Setenil, Málaga). Gota a gota, 17, 1-6.

Molina, E. 1977. Estudio micromorfológico de las alteraciones que afectan a las calizas de facies Páramo en antiguos perfiles pliocenos. Acta geológica hispánica, 12(1), 38-41.

Molina, E., Armenteros, I. 1986. Los arrasamientos Plioceno y Plio Pleistoceno en el Sector Sur-Oriental de la Cuenca del Duero. Studia Geologica Salmanticensia, 22, 293-307. 
Nozal, F., Herrero, A. 2005. El Mioceno del borde Meridional del Corredor Aranda de Duero-Burgo de Osma (SE cuenca del Duero). Revista de la Sociedad Geológica de España, 18(1-2), 21-37.

Ordóñez, S., López Aguayo, F., García del Cura, M. A. 1976. Estudio Geológico de las "facies rojas" pliocuaternarias del borde SE de la Cuenca del Duero (provincia de Segovia). Estudios geológicos, 32, 215-220.

Ortega, J. M. 2019. La conquista islámica de la península Ibérica. Una perspectiva arqueológica. Serie Arqueología y Patrimonio 14. La Ergástula. Madrid. 416 pp.

Palol, P. de, 1983. Un vidrio tallado, con temas cristianos, de Clunia. Ginouves, R. (ed.) Mosaïque, recueil d'hommages à Henri Stern. Editions Recherche sur les civilisations, Paris, 281-286.

Palol, P. de, Vilella, J. 1986. ¿Un santuario priápico en Clunia? Koiné, 2, 15-25.

Palol, P. de, Vilella, J. 1988 a. Clunia II La epigrafía de Clunia, Excavaciones arqueológicas en España, 150. Subdirección General de Arqueología y Etnografía, Madrid. 183 $\mathrm{pp}$.

Palol, P. de, Vilella, J. 1988 b. Inscripciones en el Santuario Priápico, Clunia II. La epigrafía de Clunia. Subdirección General de Arqueología y Etnografía. Madrid, 129-137.

Palol, P. 1994, Historia de la ciudad y guía de las excavaciones. Diputación provincial de Burgos. 148 pp.

Parise, M., Sammarco, M. 2015. The historical use of water resources in karst. Environmental earth sciences, 74 (1), 143-152.

Porres Benito, J.A., 2003. Caracterización de cavidades en el subsuelo mediante la interpretación de perfiles de Tomografía Eléctrica: Aplicación al yacimiento arqueológico de Clunia. Tesis doctoral. U. de Burgos.

Porres Benito, J. A., Ibáñez, S. J., Ortiz-Palacio, S., LópezAusín, V. 2016. Fractures location on karstified limestone surfaces by Electrical Resistivity Tomography Characte- rization. En Lehane, B. M., Acosta-Martínez, H. E., Kelly, $\mathrm{R}$ (ed.), Geotechnical and Geophysical Site Characterization, 929-933.

Puche, O., González Aguado, M. 1992. La piedra monumental en Castilla-León: Limpieza. Roc Maquina, (22), 18-32.

Rodríguez Ceballos. M. 2016. La cueva de Román. Nuevas hipótesis para entender Clunia Sulpicia. Tesis doctoral. Universidad de Alcalá de Henares, 1070 pp.

Santos Yanguas, N. V. 1979. Formas de propiedad y producción en el Noroeste hispánico en época romana altoimperial. Memorias de historia antigua, (3), 63-72.

Sentenach, N. 1914. Los arévacos. Imprenta de la Revista de Archivos y Bibliotecas. Madrid, 113 pp.

Serrano-Ortiz, P., Roland, M., Sanchez-Moral, S., Janssens, I. A., Domingo, F., Goddéris, Y., Kowalski, A. S. 2010. Hidden, abiotic $\mathrm{CO}_{2}$ flows and gaseous reservoirs in the terrestrial carbon cycle: Review and perspectives. Agricultural and Forest Meteorology, 150(3), 321-329.

Taracena, B., Huguet, P. B., Schlunk, H. 1947. Ars Hispaniae, T II, Plus Ultra. Madrid. 441 pp.

Valdés, L., Reina, F. J. 2004. Informe de la investigación del Sistema Kárstico del Cerro de Clunia y de la Geología local y regional. Método Directo y Método Geofísico. Peñalba de Castro (Burgos). Informe inédito, Biblioteca de la casa de la Excavación. Clunia.

Tuset, F., Martínez, G., Cuesta, R. 2015. Localización y vaciado de un pozo para el acceso al karst de "Cueva Román". Informe inédito. Diputación Provincial de Burgos. Expediente 35/2014.

Valdés, L., Reina, F. J. 2006. Informe de la investigación por Método Geofísico para la localización de la Atarjea de Drenaje del Teatro de Clunia, Peñalba de Castro (Burgos), Informe inédito, Biblioteca de la casa de la Excavación. Clunia.

Wilde, S. 1990. The Bathonian and Callovian of the Northwest-Iberian Range: Stages of facial paleogeographical differentiation on an epicontinental platform. Cuadernos de Geología Ibérica, 14, 113-142

Recibido: julio 2019

Revisado: noviembre 2019

Aceptado: enero 2020

Publicado: marzo 2021 